\title{
Molecular basis for the distinct cellular functions of the Lsm1-7 and Lsm2-8 complexes
}

\author{
ERIC J. MONTEMAYOR, ${ }^{1,2}$ JOHANNA M. VIRTA, ${ }^{1}$ SAMUEL M. HAYES, ${ }^{1}$ YUICHIRO NOMURA, ${ }^{1}$ \\ DAVID A. BROW, ${ }^{2}$ and SAMUEL E. BUTCHER ${ }^{1}$ \\ ${ }^{1}$ Department of Biochemistry, University of Wisconsin-Madison, Madison, Wisconsin 53706, USA \\ ${ }^{2}$ Department of Biomolecular Chemistry, University of Wisconsin School of Medicine and Public Health, Madison, Wisconsin 53706, USA
}

\begin{abstract}
Eukaryotes possess eight highly conserved Lsm (like Sm) proteins that assemble into circular, heteroheptameric complexes, bind RNA, and direct a diverse range of biological processes. Among the many essential functions of Lsm proteins, the cytoplasmic Lsm1-7 complex initiates mRNA decay, while the nuclear Lsm2-8 complex acts as a chaperone for U6 spliceosomal RNA. It has been unclear how these complexes perform their distinct functions while differing by only one out of seven subunits. Here, we elucidate the molecular basis for Lsm-RNA recognition and present four high-resolution structures of Lsm complexes bound to RNAs. The structures of Lsm2-8 bound to RNA identify the unique $2^{\prime}, 3^{\prime}$ cyclic phosphate end of $U 6$ as a prime determinant of specificity. In contrast, the Lsm1-7 complex strongly discriminates against cyclic phosphates and tightly binds to oligouridylate tracts with terminal purines. Lsm5 uniquely recognizes purine bases, explaining its divergent sequence relative to other Lsm subunits. Lsm1-7 loads onto RNA from the $3^{\prime}$ end and removal of the Lsm1 carboxy-terminal region allows Lsm1-7 to scan along RNA, suggesting a gated mechanism for accessing internal binding sites. These data reveal the molecular basis for RNA binding by Lsm proteins, a fundamental step in the formation of molecular assemblies that are central to eukaryotic mRNA metabolism.
\end{abstract}

Keywords: Lsm1-7; Lsm2-8; RNA binding proteins; U6 snRNA; X-ray crystallography

\section{INTRODUCTION}

The Lsm/Sm proteins are an ancient family of RNA binding proteins found in all three domains of life and have a wide range of biological functions. They are named after the autoimmune patient serum that led to their discovery (Tan and Kunkel 1966; Lerner and Steitz 1979). The Sm family includes the Sm, Lsm ("Like Sm"), and bacterial Hfq proteins (Wilusz and Wilusz 2013). These proteins share a conserved "Sm fold" consisting of an amino-terminal alpha helix followed by five antiparallel beta strands that form small beta barrels that assemble into ring-shaped hexamers or heptamers. The eukaryotic Sm proteins form heteroheptamers that interact with the major spliceosomal snRNAs U1, U2, U4, and U5, the minor spliceosomal snRNAs U4 ${ }^{\text {atac }}$, U11, U12, and telomerase RNA. The Smlike archaeal proteins (SmAPs) are homologous to the eukaryotic Sm proteins, but their biological roles are less well understood (Mura et al. 2013). The eukaryotic Lsm proteins form at least four different six- or seven-subunit

Corresponding authors: emontemayor@wisc.edu, sebutcher@wisc.edu

Article is online at http://www.rnajournal.org/cgi/doi/10.1261/rna. 075879.120. Freely available online through the RNA Open Access option. complexes (Wilusz and Wilusz 2013). In addition, a hybrid complex containing Lsm10, Lsm11, and five Sm proteins is essential for $3^{\prime}$ end processing of histone mRNAs (Dominski and Marzluff 2007; Sun et al. 2020).

The Lsm1-7 complex is cytoplasmic and mediates messenger-RNA (mRNA) decay, a major posttranscriptional mechanism for regulating gene expression (Bouveret et al. 2000; Tharun et al. 2000; Moore 2005; Parker 2012). Binding of the Lsm1-7 complex to mRNA is a key event in the decay pathway as it also binds the protein Pat1 (Chowdhury et al. 2007; Sharif and Conti 2013; Lobel et al. 2019). Pat1 then recruits a complex consisting of the decapping enzyme Dcp2 and its activators Dcp1, Edc1, and Edc2 (Mugridge et al. 2018). After decapping, the $5^{\prime}-3^{\prime}$ exoribonuclease Xrn1 degrades the mRNA. Structures have been determined for the isolated $S$. cerevisiae Lsm1-7 complex (Sharif and Conti 2013; Zhou et al. 2014b), and the S. cerevisiae Lsm1-7 with a carboxy-terminally truncated Lsm1 bound to the carboxy-terminal domain of Pat1 (Sharif and Conti 2013; Wu et al. 2014). However, no structures are available for Lsm1-7 bound

(C) 2020 Montemayor et al. This article, published in RNA, is available under a Creative Commons License (Attribution 4.0 International), as described at http://creativecommons.org/licenses/by/4.0/. 
to RNA, despite the central importance of this interaction in the mRNA decay pathway. In addition to activating mRNA decapping, Lsm1-7 has many other functions including formation of phase-separated processing bodies (P-bodies) (Decker et al. 2007; Reijns et al. 2008), protecting $3^{\prime}$ ends of mRNA from $3^{\prime}-5^{\prime}$ degradation by the exosome ( $\mathrm{He}$ and Parker 2001; Tharun et al. 2005), stabilizing specific RNAs during starvation and autophagy (Gatica et al. 2019), suppressing translation of stress-activated RNAs during osmotic shock (Garre et al. 2018), and promoting translation of viral RNAs (Jungfleisch et al. 2015). Human and Schizosaccharomyces pombe Lsm1-7 complexes bind tightly to oligouridylate (hereafter, oligoU) RNAs (Lyons et al. 2014; Lobel et al. 2019). In contrast, the Lsm1-7-Pat1 complex binds tightly to oligoadenylate (hereafter, oligoA) RNAs (Chowdhury et al. 2007, 2014; Lobel et al. 2019). The molecular basis for these interactions is unknown.

The Lsm2-8 complex shares six out of seven subunits with Lsm1-7, localizes in the nucleus, and binds the $3^{\prime}$ ends of U6 and U6 ${ }^{\text {atac }}$ snRNAs (Mayes et al. 1999; Reijns et al. 2009; Zhou et al. 2014a; Montemayor et al. 2018). U6 snRNA is transcribed by RNA polymerase III, which terminates transcription after synthesis of an oligoU tail at the end of U6 snRNA (Didychuk et al. 2018). This tail can then be elongated by the enzyme Tutase (Didychuk et al. 2018). Finally, U6 snRNA is processed by the $3^{\prime}-5^{\prime}$ exoribonuclease Usb1 (Didychuk et al. 2018), resulting in a 2',3' cyclic phosphate in most organisms (Fig. 1; Lund and Dahlberg 1992). In addition, Lsm2-8 mediates nuclear mRNA decay (Kufel et al. 2004). In the case of S. pombe, Lsm2-8 is also known to play an important role in telomerase biogenesis (Tang et al. 2012).

The molecular basis for the Lsm2-8 interaction with U6 snRNA terminating in a cyclic phosphate has yet to be elucidated, despite existing cryo-EM structures of the human U4/U6.U5 tri-snRNP (Agafonov et al. 2016) and pre-B complex (Charenton et al. 2019), both of which contain the Lsm2-8 complex bound to U6 snRNA. In these structures,

A
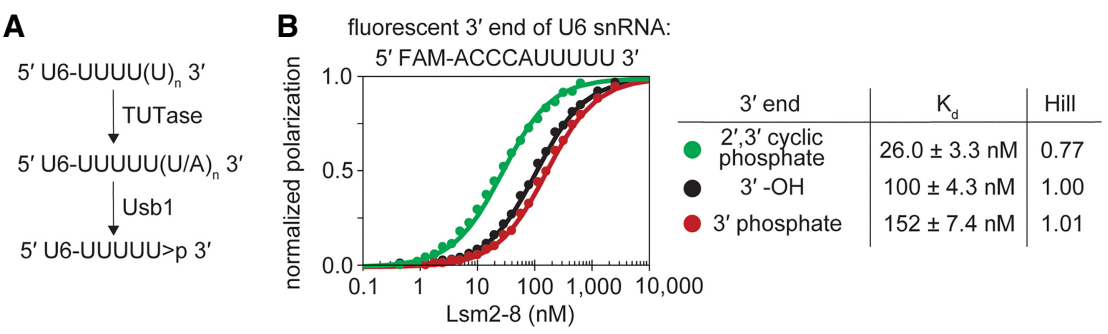

FIGURE 1. 3 '-processing of U6 snRNA alters its recognition by S. pombe Lsm2-8. (A) Processing of U6 by Usb1 leaves a 3' cyclic phosphate group on U6, denoted as ">p." (B) In vitro fluorescence polarization binding assays show that $S$. pombe Lsm2-8 preferentially binds RNA that has been processed by Usb1. All binding curves and $K_{d}$ determinations in this work were performed with a restrained Hill coefficient of 1 . For reference, the nonrestrained Hill coefficients, which are close to 1 , are shown in the figure. the U6 snRNA-Lsm2-8 complex can only be resolved to resolutions of $\sim 10 \AA$, due to its location on the surface of these complexes and/or dynamic motions. The $S$. cerevisiae Lsm2-8 structure has been determined (Zhou et al. 2014a; Montemayor et al. 2018) but is unlikely to be representative of most eukaryotes due to significant differences in Lsm8 protein sequence and U6 snRNA posttranscriptional modification (Didychuk et al. 2017). Budding yeasts have Usb1 enzymes that open the $2^{\prime}, 3^{\prime}$ cyclic phosphate to produce a $3^{\prime}$ phosphate, and their Lsm8 proteins have evolved a unique carboxy-terminal extension in order to interact with this $3^{\prime}$ phosphate through electrostatic interactions (Didychuk et al. 2017; Montemayor et al. 2018). In contrast, the Lsm8 proteins of most eukaryotes, from S. pombe to humans, do not have this Lsm8 extension and have U6 snRNAs with terminal $2^{\prime}, 3^{\prime}$ cyclic phosphates. The relative specificity of the Lsm2-8 interaction with U6 versus other RNAs is also not well understood.

Here, we investigate the binding properties of Lsm1-7 and Lsm2-8 complexes from $S$. pombe. We show that Lsm2-8 specifically recognizes the terminal $2^{\prime}, 3^{\prime}$ cyclic phosphate while still retaining the ability to bind unmodified RNA. We reveal the molecular basis for Lsm2-8 binding by determining high-resolution structures of Lsm2-8 complexes bound to two RNAs, one that is unmodified and one that has a $2^{\prime}, 3^{\prime}$ cyclic phosphate. Next, we describe the RNA binding properties of the Lsm1-7 complex utilizing a panel of RNAs of varying lengths and sequences. We report two high-resolution structures of Lsm1-7 bound to high affinity RNA targets that explain the molecular basis of Lsm1-7-RNA recognition. We demonstrate that Lsm1-7 loads unidirectionally onto RNA from the $3^{\prime}$ end, using a binding mechanism in which specificity is bestowed by the Lsm 1 carboxy-terminal region. Removal of this region enables $3^{\prime}-5^{\prime}$ scanning and leads to a model for allosteric regulation of mRNA decay. In summary, the RNA binding activities of Lsm1-7 and Lsm2-8 are remarkably distinct despite similar quaternary structures that differ by only one subunit.

\section{RESULTS}

\section{The Lsm2-8 complex specifically recognizes oligoU with a $2^{\prime}, 3^{\prime}$ cyclic phosphate}

Schizosaccharomyces pombe Lsm proteins were coexpressed in E. coli and orthogonal affinity tags were used to purify the Lsm1-7 and Lsm2-8 complexes (Supplemental Fig. 1). For Lsm2-8, we demonstrated that the complex can bind to U6 snRNA 
TABLE 1. Diffraction data collection and structure refinement statistics

\begin{tabular}{|c|c|c|c|c|}
\hline Protein RNA & Lsm2-8 UUUUU & Lsm2-8 UUUUU >p & Lsm $1_{\Delta 56 C}-7$ UUUUUA & $\operatorname{Lsm}_{\Delta 56 \mathrm{C}}-7$ AUUUUG \\
\hline PDB ID & 6PPN & 6PPP & $6 \mathrm{PPQ}$ & 6PPV \\
\hline Wavelength $(\AA ̊)$ & 0.9792 & 1.0781 & 0.9762 & 0.9763 \\
\hline Resolution range (Å) & $168-1.90(2.08-1.90)$ & $78.0-2.33$ (2.73-2.33) & $98.8-1.81(1.88-1.81)$ & $98.7-2.05$ (2.11-2.05) \\
\hline Space group & $P 2{ }_{1} 2{ }_{1} 2$ & $P 2{ }_{1} 2{ }_{1} 2$ & $P 3,21$ & $P 3,21$ \\
\hline Unit cell (Å) & 70.3135 .4168 .0 & 70.3139 .7153 .9 & 68.968 .9296 .3 & 69.069 .0296 .1 \\
\hline Total reflections ${ }^{a}$ & $1,101,742(46,024)$ & $2,493,903(104,496)$ & $2,384,574(75,834)$ & $1,117,285(89,763)$ \\
\hline Unique reflections ${ }^{a}$ & $80,785(4,039)$ & $28,712(1,433)$ & $75,844(4,347)$ & $52,874(4.047)$ \\
\hline Multiplicity ${ }^{a}$ & $13.6(11.4)$ & $86.9(72.9)$ & $31.4(17.4)$ & $21.1(22.2)$ \\
\hline \multicolumn{5}{|l|}{ Completeness (\%) } \\
\hline spherical & $63.3(13.4)$ & $43.7(5.9)$ & $100.0(99.4)$ & $100(100)$ \\
\hline ellipsoidal & $96.2(74.4)$ & $94.9(74.6)$ & NA & NA \\
\hline Anisotropic $\Delta \mathrm{B}\left(\AA^{2}\right)$ & 32.4 & 83.4 & 10.1 & 7.4 \\
\hline Mean $I / \sigma(I)^{a}$ & $17.2(1.8)$ & $16.0(2.2)$ & $15.4(0.4)$ & $11.6(0.9)$ \\
\hline$R_{\text {merge }}{ }^{a}$ & $0.074(1.355)$ & $0.293(3.347)$ & $0.125(7.075)$ & $0.159(4.145)$ \\
\hline$R_{\text {pim }}{ }^{a}$ & $0.021(0.401)$ & $0.032(0.392)$ & $0.022(1.698)$ & $0.036(0.897)$ \\
\hline $\mathrm{CC}_{1 / 2}{ }^{\mathrm{a}}$ & 0.999 (0.729) & $0.999(0.876)$ & 0.999 (0.409) & $0.999(0.380)$ \\
\hline \multicolumn{5}{|l|}{ Refinement } \\
\hline Resolution & $67.7-1.91$ (1.98-1.91) & $51.7-2.33(2.41-2.33)$ & $34.5-1.81(1.88-1.81)$ & $42.1-2.05(2.12-2.05)$ \\
\hline$R_{\text {work }} / R_{\text {free }}{ }^{a}$ & $0.20 / 0.23(0.34 / 0.27)$ & $0.22 / 0.28(0.62 / 0.63)$ & $0.19 / 0.22(0.36 / 0.40)$ & $0.21 / 0.25(0.35 / 0.38)$ \\
\hline Total atoms & 8877 & 8841 & 4677 & 4577 \\
\hline macromolecules & 8783 & 8815 & 4375 & 4387 \\
\hline ligands & 0 & 0 & 0 & 0 \\
\hline water & 94 & 26 & 302 & 190 \\
\hline RMS(bonds) & 0.009 & 0.013 & 0.006 & 0.005 \\
\hline RMS(angles) & 1.19 & 1.95 & 0.89 & 0.87 \\
\hline Ramachandran favored & $97.9 \%$ & $98.0 \%$ & $98.3 \%$ & 96.3 \\
\hline Ramachandran outliers & $0 \%$ & $0 \%$ & $0 \%$ & $0 \%$ \\
\hline Average ADP $\left(\AA^{2}\right)$ & 66.9 & 85.7 & 51.5 & 50.9 \\
\hline macromolecules & 67.1 & 85.8 & 50.9 & 50.8 \\
\hline ligands/ions & NA & NA & NA & NA \\
\hline solvent & 47.5 & 46.0 & 60.6 & 55.4 \\
\hline
\end{tabular}

STARANISO (Tickle et al. 2018) was used to perform ellipsoidal truncation for data sets 6PPN and 6PPP. After ellipsoidal truncation the weakest direction of diffraction data extended to $2.75 \AA$ for PDB 6PPN and $3.60 \AA$ for PDB 6PPP. Data from ellipsoidal truncation accompany the coordinate sets deposited in the Protein Data Bank. For PDBs 6PPN and 6PPP, merged diffraction data that has not been subjected to ellipsoidal truncation is available as Supplemental Data File 2, along with the final refined coordinates, structure factors and phases for all structures reported here. A summary PyMOL session file is available as Supplemental Data File 3.

${ }^{a}$ Values in parentheses are for the highest resolution shell.

and further associate with protein Prp24 to form the complete U6 snRNP, a known interaction previously observed for the S. cerevisiae U6 snRNP (Montemayor et al. 2018). We wished to determine if the Lsm2-8 ring specifically recognizes the $2^{\prime}, 3^{\prime}$ cyclic phosphate group at the end of U6 snRNA, and if so, how. We therefore used fluorescence polarization to measure and compare the binding affinities of Lsm2-8 for oligoribonucleotides corresponding to the $3^{\prime}$ oligoU tail of U6 terminating with a $2^{\prime}, 3^{\prime}$ cyclic phosphate group, a 3' phosphate, or an unmodified 3' hydroxyl (Fig. 1B; Supplemental Table 1).
We find that Lsm2-8 binds tightly to an RNA oligonucleotide with a 2', $3^{\prime}$ cyclic phosphate group, and fourfold less tightly to the unmodified RNA with a $3^{\prime}$ hydroxyl $\left(K_{d}=26\right.$ and $100 \mathrm{nM}$, respectively) (Fig. 1B). This fourfold difference suggests specific recognition of the $2^{\prime}, 3^{\prime}$ cyclic phosphate group. Interestingly, Lsm2-8 binds to an oligonucleotide terminating in a $3^{\prime}$ phosphate least tightly of all with a $K_{d}$ of $152 \mathrm{nM}$. Thus, the Lsm2-8 complex preferentially binds to oligonucleotides terminating in a $2^{\prime}, 3^{\prime}$ cyclic phosphate group while still retaining ability to bind to unmodified RNA, and can somehow strongly discriminate 
between $2^{\prime}, 3^{\prime}$ cyclic phosphate and noncyclic $3^{\prime}$ phosphate groups.

\section{Structures of Lsm2-8-RNA complexes}

We crystallized the Lsm2-8 complex bound to UUUUU-3'-OH and UUUUU $>p$ and determined their structures by $X$-ray diffraction to resolutions of 1.9 and $2.3 \AA$, respectively (Table 1 ). In the Lsm2-8 complex bound to the UUUUU-3'-OH RNA, the $5^{\prime}$ uridine is bound by Lsm4, and the next three uridines are bound sequentially by Lsm8, Lsm2, and Lsm3 (Fig. 2A, C). Uridine binding involves stacking and an extensive hydrogen bonding network as previously described (Fig. 2E; Zhou et al. 2014a; Montemayor et al. 2018). The last uridine with the $3^{\prime}-\mathrm{OH}$ group is disordered except for its $5^{\prime}$ phosphate as evidenced by weak electron density for both the ribose and uracil groups (Supplemental Fig. 2a). We confirmed that the RNA remains completely intact after prolonged incubation with Lsm2-8, further supporting the idea that the last uridine is covalently attached but disordered in the structure (Supplemental Fig. 2b).

In contrast to the Lsm2-8 complex with unmodified RNA, the structure of the Lsm2-8 ring bound to UUUUU $>p$ reveals that the last nucleotide is highly ordered (Supplemental Fig. $2 c, d)$. The cyclic phosphate causes the RNA chain to make a sharp turn of nearly $180^{\circ}$, which positions the terminal nucleobase to stack over the last histidine at the carboxyl terminus of Lsm8. The terminal uracil base adopts an unusual syn conformation and forms a hydrogen bond to the Lsm3-Asp83 side chain (Fig. 2F). Lsm3-Arg27 forms a hydrogen bond to a nonbridging oxygen on the terminal cyclic phosphate group and makes a salt bridge with the Lsm8 carboxy-terminal histidine carboxyl group. This binding mechanism is markedly different from that in the S. cerevisiae Lsm2-8 complex with a noncyclic phosphate, where the terminal uridine adopts an anti conformation and lacks direct contacts with the corresponding arginine and aspartate residues (Supplemental Fig. 3; Montemayor et al. 2018).
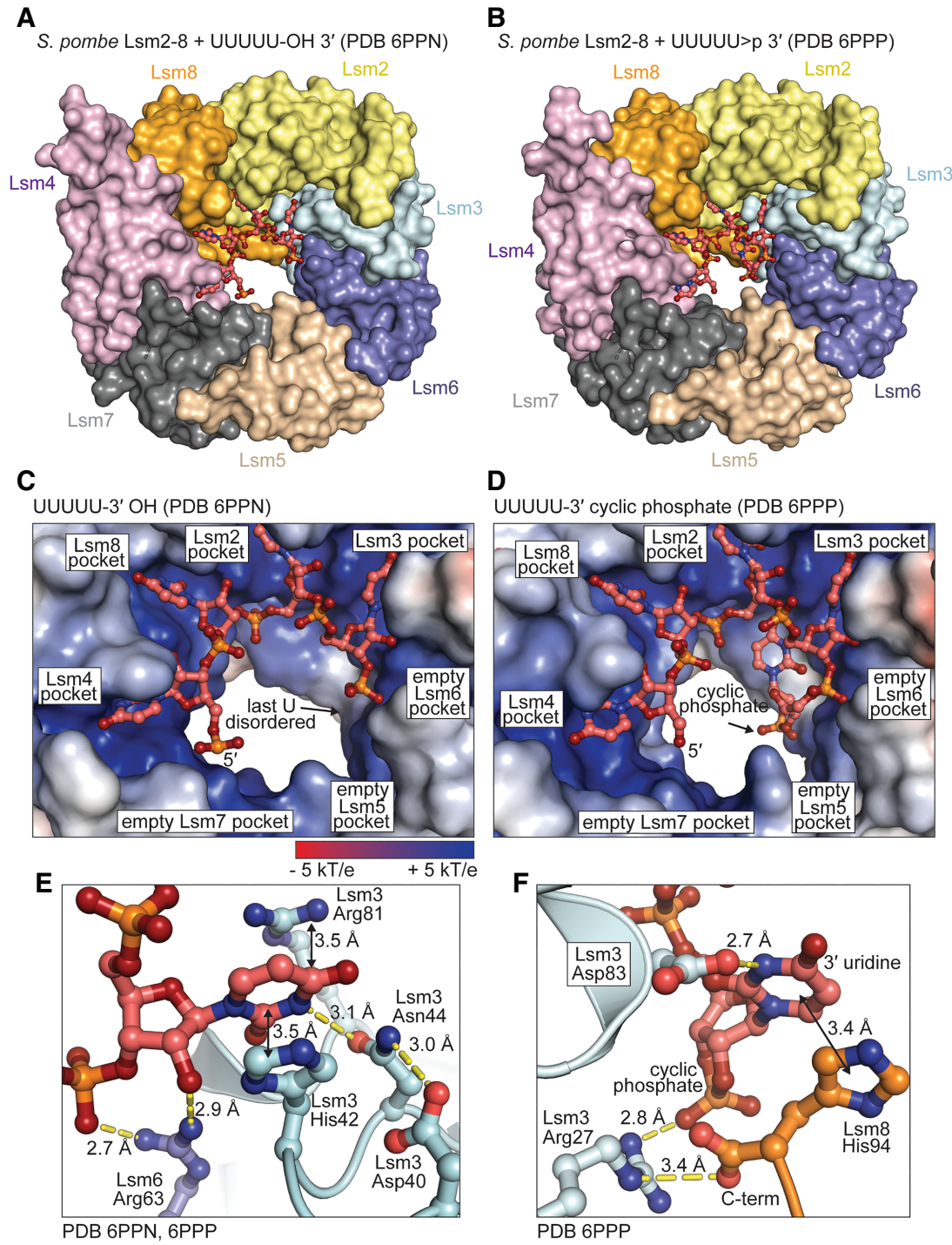

FIGURE 2. Structures of $S$. pombe Lsm2-8 bound to pentauridylate with a $2^{\prime}, 3^{\prime} \mathrm{OH}$ or $2^{\prime}, 3^{\prime \prime}$ cyclic phosphate. (A) Overview of Lsm2-8 bound to "unprocessed" U6 snRNA 3' terminus. (B) Overview of Lsm2-8 bound to "mature" U6 snRNA 3' terminus. (C) Detail of Lsm2-8 interface with "unprocessed" RNA. The $3^{\prime}$ terminal uridine is disordered and thus not visible in the final electron density maps. (D) In contrast, the mature U6 $3^{\prime}$ end, with a $2^{\prime}, 3^{\prime}$ cyclic phosphate, shows electron density for the terminal nucleotide. (E) The Sm-like pocket in Lsm3 binds RNA as observed previously in other Lsm2-8 complexes from S. cerevisiae. $(F)$ In contrast, the $3^{\prime}$ uridine cyclic phosphate has a unique binding mechanism relative to the other four uridines, including a stacking interaction with the carboxy-terminal histidine of Lsm8.

\section{RNA binding properties of the Lsm1-7 complex}

Lsm1-7 shares six out of seven subunits with Lsm2-8 and has all but one of the uridine binding pockets present in Lsm2-8. The S. cerevisiae Lsm1-7 structure in the absence of RNA has been determined and displays an overall structure that is very similar to Lsm2-8 (Fig. 3). We therefore reasoned that Lsm1-7 and Lsm2-8 might bind to similar RNA sequences. However, when superimposing the structures of S. cerevisiae Lsm2-8 bound to RNA and Lsm1-7, there 

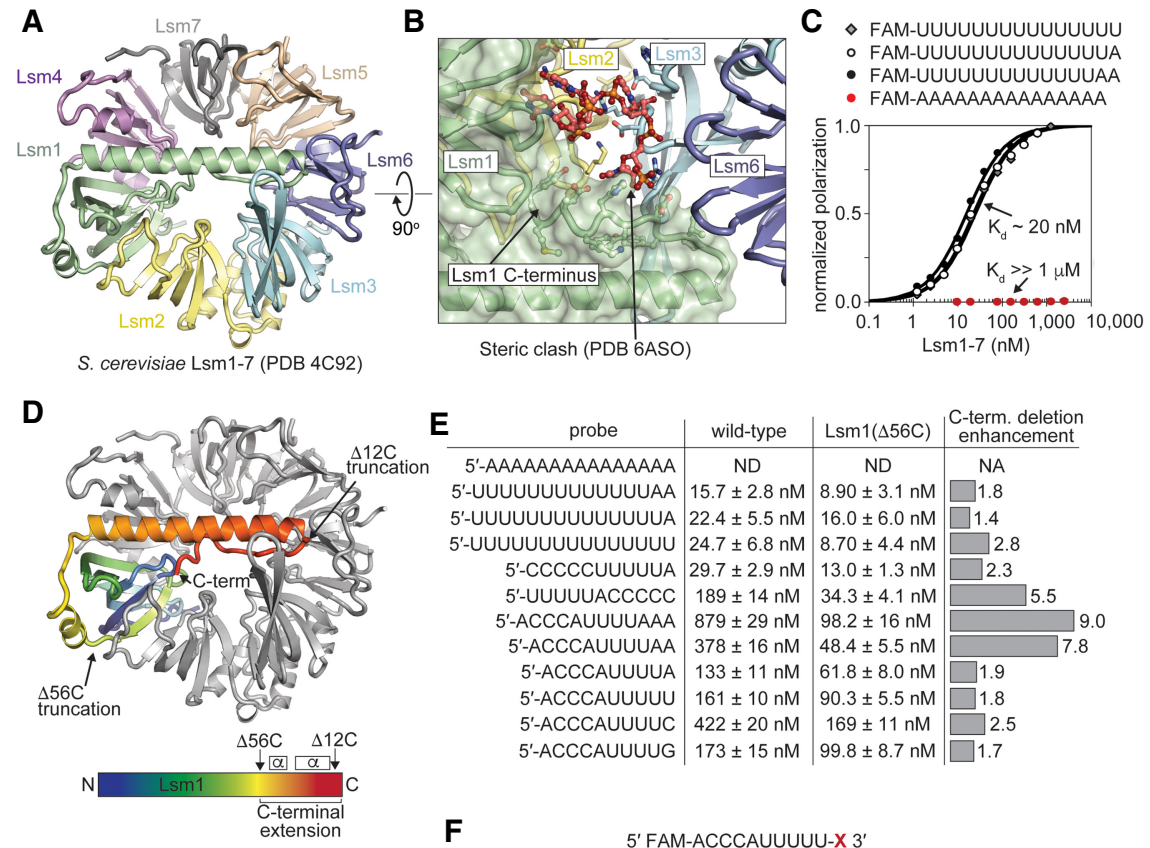

$\mathbf{E}$

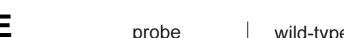

\begin{tabular}{|c|c|}
\hline Lsm1( $\Delta 56 \mathrm{C})$ & $\begin{array}{l}\text { C-term. deletion } \\
\text { enhancement }\end{array}$ \\
\hline ND & NA \\
\hline $8.90 \pm 3.1 \mathrm{nM}$ & 1.8 \\
\hline $16.0 \pm 6.0 \mathrm{nM}$ & 1.4 \\
\hline $8.70 \pm 4.4 \mathrm{nM}$ & 2.8 \\
\hline $13.0 \pm 1.3 \mathrm{nM}$ & 2.3 \\
\hline $34.3 \pm 4.1 \mathrm{nM}$ & 5.5 \\
\hline $98.2 \pm 16 \mathrm{nM}$ & \\
\hline $48.4 \pm 5.5 \mathrm{nM}$ & \\
\hline $61.8 \pm 8.0 \mathrm{nM}$ & $\square 1.9$ \\
\hline $90.3 \pm 5.5 \mathrm{nM}$ & $\square 1.8$ \\
\hline $169 \pm 11 \mathrm{nM}$ & 2.5 \\
\hline $99.8 \pm 8.7 \mathrm{nM}$ & $\square 1.7$ \\
\hline
\end{tabular}

$\mathbf{F}$

\begin{tabular}{c|c|c|c}
\multicolumn{3}{|c}{$5^{\prime}$ FAM-ACCCAUUUUU-X $3^{\prime}$} & adenosine \\
Lsm1-7 & $>p$ & adenosine & enhancement \\
\hline wild-type & $329 \pm 13 \mathrm{nM}$ & $22.9 \pm 1.1 \mathrm{nM}$ & 14.4 \\
$\operatorname{Lsm1}(\Delta 12 \mathrm{C})$ & $78.0 \pm 13 \mathrm{nM}$ & $18.7 \pm 2.7 \mathrm{nM}$ & 4.2
\end{tabular}

FIGURE 3. The elongated carboxy-terminal region of Lsm1 in the S. pombe Lsm1-7 ring attenuates RNA binding. (A) Structure of the S. cerevisiae Lsm1-7 ring in the absence of bound RNA. The carboxy-terminal region of Lsm1 crosses the distal face of the ring, occluding the central pore. (B) Superposition of U6 snRNA from the homologous S. cerevisiae Lsm2-8 ring with the $S$. cerevisiae Lsm1-7 ring. The alignment in this figure was achieved by superposition of Lsm2, Lsm3, and Lsm6 components of the rings, which share a pairwise r.m.s.d of $0.5 \AA$. A steric clash is visible between the $3^{\prime}$ uridine phosphate and the carboxy-terminal region of Lsm1. (C) In vitro fluorescence polarization binding assays show that S. pombe Lsm1-7 tightly binds to polyuridylate tracts without accessory proteins, like Pat1. In contrast, S. pombe Lsm17 lacks detectable affinity for polyadenylate. (D) Designed truncations of the Lsm1 carboxyl terminus. Lsm 1 is colored blue to red from the amino- and carboxyl-termini, respectively, and regions selected for truncation are annotated in the figure, resulting in truncation of the last 12 residues that fold back into the pore, or truncation of the entire helical region that spans the distal face of the ring. (E) Binding assays showing that deletion of the Lsm1 carboxy-terminal region generally enhances binding affinity for RNAs that harbor polyuridine tracts, and the relative enhancement is greatest for the weakest binding RNAs. (F) A strong preference for an adenosine $3^{\prime}$ terminus over a uridine cyclic phosphate $3^{\prime}$ terminus is diminished upon deletion of the carboxy-terminal 12 residues of Lsm1.

is steric clash between the $3^{\prime}$-end of the RNA and the carboxy-terminal domain of Lsm1 (Fig. 3B). This may explain why the S. cerevisiae Lsm1-7 ring alone has been reported to not bind to RNA (Chowdhury et al. 2014).

Since S. pombe Lsm1-7 has been observed to bind to oligoU RNAs as well as oligoA RNAs in the presence of Pat1 (Lobel et al. 2019), we first analyzed binding to four 15mers: U15, U14A, U13AA, and A15 under stringent binding conditions including $0.1 \mathrm{mg} / \mathrm{mL}$ competitor tRNA, $0.1 \mathrm{mg} / \mathrm{mL}$ sodium heparin, and $0.1 \mathrm{mg} / \mathrm{mL}$ BSA. We find that U15, U14A, and U13AA all bind tightly to Lsm1-7; in contrast, A15 does not bind in our assay (Fig. $3 C$ ). Owing to the observed potential for steric clash between RNA and the carboxyl terminus of Lsm1, we also compared RNA binding to a variant of Lsm1-7 in which the last 56 amino acids of Lsm1 were removed (Lsm1 $\left.1_{\triangle 56 \mathrm{C}}-7\right)$ (Fig. 3D). Lsm $1_{\Delta 56 \mathrm{C}}-7$ binds even more tightly to the oligoU RNAs and, like Lsm1-7, also does not bind to A15 (Fig. 3E). Upon observing high affinity binding of Lsm1-7 to oligoU RNAs, we assayed RNAs with shorter U-tracts for binding. Lsm1-7 and $\mathrm{Lsm} 1_{\triangle 56 \mathrm{C}}-7$ binds tightly to the oligo CCCCCUU UUUA ( $K_{d}=29.7$ and $13 \mathrm{nM}$, respectively), which is comparable to the binding observed for longer oligoU tracts (Supplemental Table 1). The oligo ACCCAUUUUU binds less tightly than U15, indicating that the length of the oligoU tract plays a role in binding affinity.

In general, the Lsm $1_{\triangle 56 \mathrm{C}}-7$ construct has higher affinity for RNAs than Lsm1-7 (Fig. 3E). When the oligoU tract is at or near the $3^{\prime}$ end, the difference in binding affinities between Lsm1-7 and Lsm $1_{\triangle 56 C^{-7}}$ is approximately twofold. However, if the oligoU tract is followed by two or more $3^{\prime}$ nucleotides, the binding enhancement afforded by the Lsm1 carboxy-terminal deletion becomes much more significant (five- to ninefold). For example, the oligonucleotide UUUUUACCCCC binds poorly to Lsm1-7 $\left(K_{d}=189 \mathrm{nM}\right)$ and tightly to Lsm1 $_{\triangle 56 \mathrm{C}}-7 \quad\left(K_{d}=34 \mathrm{nM}\right)$ (Fig. 3E). These data indicate that high affinity binding sites for the Lsm1-7 complex must be at the $3^{\prime}$ termini of RNA. On the other hand, the carboxy-terminally truncated Lsm1-7(Lsm1 $\left.{ }_{\triangle 56 \mathrm{C}}-7\right) \mathrm{com}-$ plex can bind tightly to the UUUUA sequence irrespective of its position in the RNA. Thus, the Lsm1 carboxy-terminal extension functions to prevent high affinity binding to RNA, except for $3^{\prime}$ terminal sites. We further tested the effect of 3 '-end nucleotide identity on binding and found that tetrauridylate followed by a single adenosine binds more tightly than an RNA with a pentauridylate tract (Fig. 3E).

Interestingly, we observe that the carboxy-terminal 12 residues of Lsm 1 strongly discriminates against cyclic phosphate RNAs. Comparison of a monoadenylated RNA and a cyclic phosphate RNA shows an approximate 14-fold reduction in binding affinity for the cyclic phosphate RNA, which is substantially attenuated by deleting only a small region from the carboxyl terminus of Lsm1 (Fig. 3D,F). 
A S. pombe Lsm1-7 + UUUUUA (PDB 6PPQ)

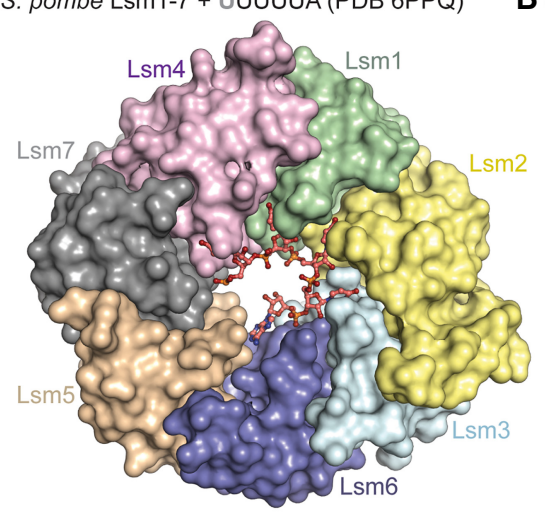

B S. pombe Lsm1-7 + AUUUUG (PDB 6PPV)

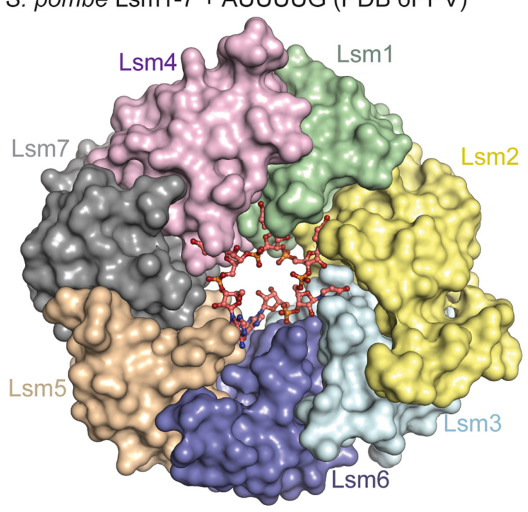

C UUUUUA (PDB 6PPQ)

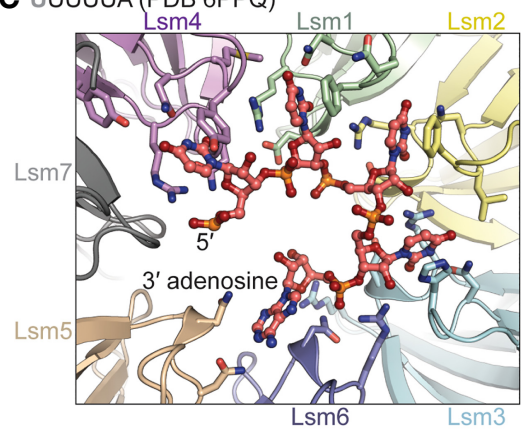

D AUUUUG (PDB 6PPV)

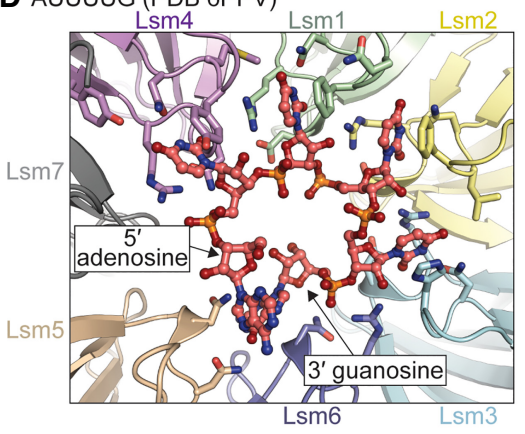

E UUUUUA (PDB 6PPQ)

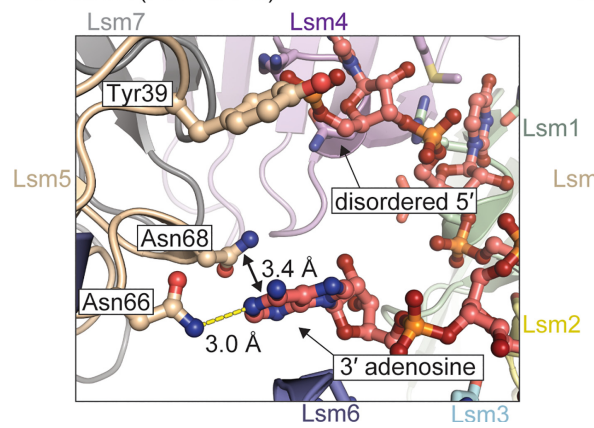

F AUUUUG (PDB 6PPV)

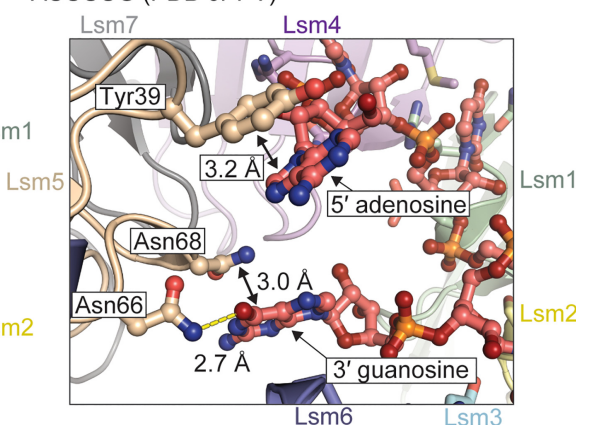

FIGURE 4. The structure of S. pombe Lsm1-7 bound to RNA. (A) Overview of Lsm1-7 bound to UUUUA. (B) Overview of Lsm1-7 bound to AUUUUG. (C) RNA-binding interface of Lsm1-7 bound to UUUUA, showing that four uracil bases bind in the same manner as in the Lsm2-8 complex, while the adenosine binds into non-Sm pocket in Lsm5. (D) Lsm1-7 bound to AUUUUG, showing a similar binding mechanism as in $C$. $(E, F)$ Detailed view of the non-Sm Lsm 5 binding pocket occupied by adenine or guanine. In both cases, the $3^{\prime}$ purine is coordinated through hydrogen bonding with Lsm5-Asn66 and stacking with Lsm5-Asn68.

and AUUUUG and determined their structures to resolutions of 1.8 and $2.1 \AA$, respectively (Table 1; Fig. 4). In the structure of UUUUUA bound to $L s m 1_{\triangle 56 C}-7$, the first uridine is disordered and not visible in the electron density (Fig. 4A,C; Supplemental Fig. 4). The next four uridines occupy pockets in Lsm4, Lsm1, Lsm2, and Lsm3, respectively. The terminal adenosine reaches across Lsm6 to form a hydrogen bond to Asn66 of Lsm5 (Fig. 4E). This is the first observation of Lsm5 interacting with RNA; Lsm5 is not utilized in the Lsm2-8 structures. Furthermore, Lsm5 is the only Lsm protein out of the eight studied here that has a noncanonical nucleobase binding pocket because it is missing the arginine that typically forms a cation-pi stack with uracil (Fig. 2E; Zhou et al. 2014a,b; Montemayor et al. 2018). In place of arginine, Lsm5 has an asparagine (Asn66) that forms a hydrogen bond to the terminal adenine. Interestingly, this noncanonical asparagine in the Lsm5 binding pocket is highly conserved (Supplemental Data File 4).

In the structure of $\mathrm{Lsm}_{\triangle 56 \mathrm{C}}-7$ bound to AUUUUG, all nucleotides are visible within the electron density map. The path of the RNA around the interior of the Lsm1-7 torus is a right-handed helix, with the phosphodiester backbone in the center and the nucleobases splayed out into binding pockets. The six nucleotides of the RNA make an almost complete turn with the last nucleotides $6 \AA$ below the first (Fig. 4D,F). The $5^{\prime}$ adenosine interacts with the noncanonical binding pocket on Lsm5 by stacking on Tyr39 (Fig. 4F). The 3' G also interacts

We conclude that the carboxy-terminal 12 amino acids of Lsm1 are important for the binding specificity of Lsm1-7.

\section{Structures of Lsm1-7 bound to RNA}

We were unable to obtain crystals of wild-type Lsm1-7 in complex with RNA. Since deletion of the carboxyl terminus of Lsm1 generally enhances binding affinity (Fig. 3E), we therefore crystallized the $\mathrm{Lsm}_{\triangle 56 \mathrm{C}} \mathrm{C}-7$ variant of the Lsm1-7 complex bound to the U-tract RNAs UUUUUA with Lsm5 by forming a hydrogen bond to Asn 66 in a manner that is similar to the interaction observed for the terminal adenine of UUUUUA, except the asparagine side chain donates a hydrogen bond to the guanine oxygen instead of an adenine nitrogen (Fig. 4E,F). The structures explain why oligonucleotides harboring these sequences bind with nearly identical affinities to $\mathrm{Lsm}_{\triangle 56 \mathrm{C}}-7$ (Fig. 3E).

Since the terminal purines are both within hydrogen bonding distance of Lsm5 Asn66 and are in van der Waals contact with Lsm5 Asn68 (Fig. 4E,F), we tested the contribution of these interactions to binding by mutating 
A

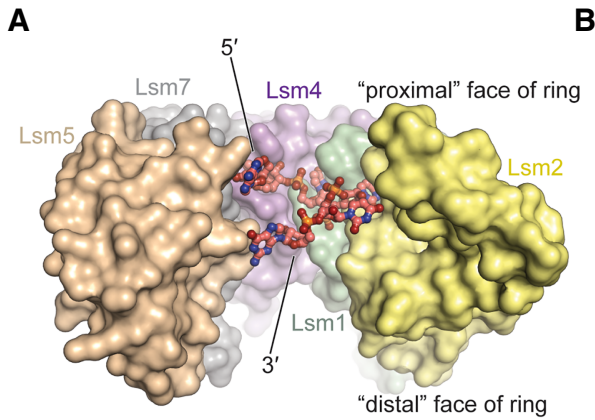

PDB 6PPV, 5'-AUUUUG-3'

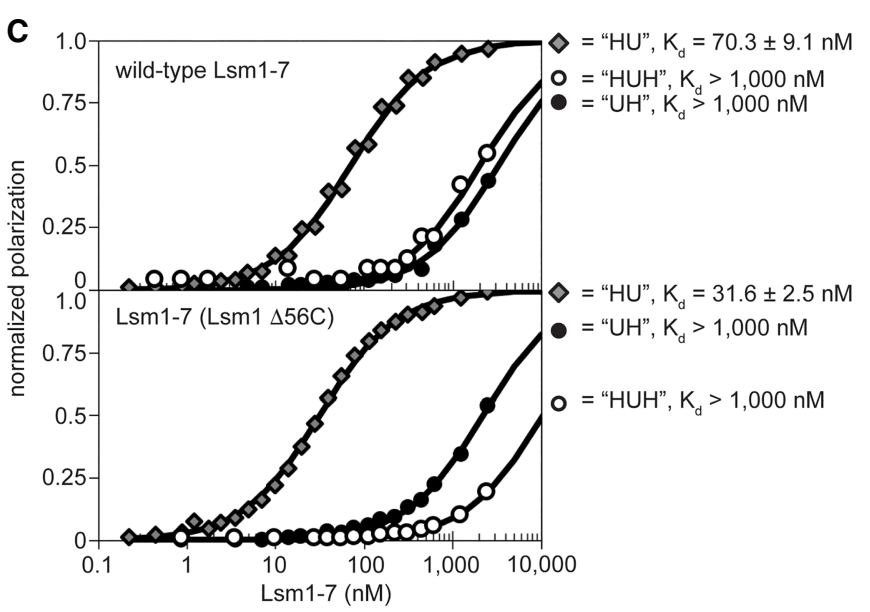

FIGURE 5. Lsm1-7 loads single stranded RNA from the $3^{\prime}$ end. (A) Cut-away view of the pore of Lsm1-7 bound to AUUUUG. Lsm3 and Lsm6 are omitted for clarity. (B) Synthetic RNAs used for binding tests, in which the $3^{\prime}$ or $5^{\prime}$ end is blocked from binding (or threading through) the pore of the Lsm1-7 ring by the presence of the hairpin structure. (C) Wild-type Lsm1-7 tightly binds the 5' hairpin RNA and has weak binding for RNAs harboring a 3' hairpin. Deletion of the carboxy-terminal region of Lsm1 does not significantly alter the binding specificity with respect to $3^{\prime}$ or $5^{\prime}$ hairpins.

Lsm5 Asn66 and Asn68 to alanine. The double mutant has a small but measurable effect upon binding RNA $\left(K_{d}=23\right.$ vs. $41 \mathrm{nM}$ ) (Supplemental Table 1). We also tested the binding specificity of the double mutant by comparing its ability to bind an RNA terminating with a cyclic phosphate versus the terminal adenosine. While Lsm1-7 can discriminate between these RNAs with a 14-fold difference in affinity, the double mutant shows only a sevenfold difference, corresponding to a twofold loss in binding specificity (Supplemental Table 1).

\section{Lsm1-7 loads onto RNA from $3^{\prime}$ ends and is blocked by secondary structure}

In the crystal structures, the $5^{\prime}$ end of the RNA hexamer is nearest the "proximal face" of Lsm1-7 while the $3^{\prime}$ end is nearest the "distal face" (Fig. 5A), the same orientation as in the Sm ring where the bound RNA passes completely through the center of the torus. This similarity suggests that single stranded RNA may be able to pass through the Lsm1-7 torus. Moreover, we reasoned that binding may man Sm ring bound to U4 snRNA

(Leung et al. 2011; Li et al. 2016) shows how directional threading of the RNA through the ring may be facilitated by conserved distal face contacts, as several residues in SmD1 and Sm2 that interact with RNA are also present in Lsm rings (Supplemental Fig. 5b).

\section{DISCUSSION}

\section{Structural basis for RNA recognition by Lsm2-8}

Phylogenetic analyses suggest that the Lsm/Sm family of proteins arose approximately 2.5 billion years ago through two waves of gene duplication, the first wave resulting in the Lsm genes from which the Sm proteins subsequently diversified (Veretnik et al. 2009). As Lsm and Sm proteins interactions are common to all spliceosomal RNAs, it is likely that these interactions arose early during the evolution of the spliceosome. The S. pombe Lsm2-8 complex is highly similar to human and other organisms (Supplemental Data File 4), so we expect the structural 
and functional data presented here to be broadly general in eukaryotic biology.

The molecular basis for Lsm2-8 binding is rationalized by the unique structural features observed in the Lsm2-8 complex bound to UUUUU $>p$. The $2^{\prime}, 3^{\prime}$ cyclic phosphate group bends the RNA chain around and stabilizes an unusual syn conformation of the terminal uracil base. Quantum chemical calculations of $2^{\prime}, 3^{\prime}$ cyclic UMP indicate that the cyclic phosphate stabilizes the syn conformation of uridine to be significantly more favored over the anti conformation (Grabarkiewicz and Hoffmann 2006). This syn conformation of the terminal uridine facilitates stacking on the Lsm8 carboxy-terminal histidine and allows for a hydrogen bond to Lsm3 Asp83, which could not happen in an anti conformation. Consistent with its central role in directly binding to the cyclic phosphate, Lsm3 Arg27 is 100\% conserved (Montemayor et al. 2018). The carboxyterminal histidine residue of Lsm8 that stacks with the terminal syn uracil nucleobase is also strongly conserved in almost all eukaryotes (Supplemental Data File 4). It is therefore clear that the carboxyl terminus of Lsm8 and nearby residues are important for specifically recognizing posttranscriptionally modified U6 snRNA (Didychuk et al. 2017; Montemayor et al. 2018).

Although S. pombe Lsm2-8 binds most tightly to oligoU with a $2^{\prime}, 3^{\prime}$ cyclic phosphate, it also must recognize heterogenous RNA sequences and different $3^{\prime}$-ends in vivo. For example, Lsm2-8 binds to telomerase RNA (TER1), which has a stretch of 3-6 uridines ending with a $3^{\prime}-\mathrm{OH}$. Consistent with this, Lsm2-8 still binds to oligoU RNA ending in $3^{\prime}-\mathrm{OH}$, with a $K_{d}$ of $100 \mathrm{nM}$. We find that Lsm2-8 also binds tightly to $3^{\prime}$ monoadenylated RNA (Supplemental Table 1). Interestingly, we note that $3^{\prime}$ monoadenylated U6 is present in human cells and is the preferred substrate for Usb1 (Hilcenko et al. 2013; Shukla and Parker 2017; Nomura et al. 2018).

\section{Unique RNA binding properties of the Lsm1-7 complex}

In contrast to Lsm2-8, the Lsm1-7 complex strongly discriminates against RNAs with a $2^{\prime}, 3^{\prime}$ cyclic phosphate by 14-fold (Fig. 3F; Supplemental Table 1). This may be to avoid certain RNAs in the cytoplasm; for example, tRNA splicing proceeds through a cyclic phosphate intermediate (Shigematsu et al. 2018). Our binding measurements indicate that Lsm1-7 binds tightly to RNAs containing poly(U) or UUUUR and loads onto RNA from the $3^{\prime}$ end. This is consistent with previous reports of Lsm1-7 binding to UA rich regions of viral genomes to regulate translation (Galao et al. 2010; Jungfleisch et al. 2015). Lsm1-7 binds tightly to the sequence AUUUUR (Fig. 3E), and this sequence is highly reminiscent of sequences found in $3^{\prime}$-UTR regions that undergo adenine/uridine-rich element (ARE) mRNA decay (Barreau et al. 2005; von Roretz et al. 2011).
Consistent with this, knockdown of Lsm1 inhibits ARE-mediated decay (Lin et al. 2007) and depletion of the Lsm1-7 binding protein Pat1b up-regulates mRNAs with AREs (Vindry et al. 2017).

Lsm1-7 preferentially loads onto single-stranded RNA from the $3^{\prime}$ end. The trajectory of the RNA in $\operatorname{Lsm}_{\Delta 56 C^{-}} 7$ suggests that the RNA can thread completely through the ring, provided the Lsm1 carboxy-terminal helix is removed or displaced. Indeed, our binding data show that RNAs with high affinity binding sites followed by additional 3 ' nucleotides (e.g., AAA or CCCCC) bind well to $\mathrm{Lsm}_{\triangle 56 \mathrm{C}}-7$ but not Lsm1-7. This is likely due to steric clash involving the Lsm1 carboxy-terminal region (Fig. 3B). The Lsm1 carboxy-terminal region may act as a gate to allow threading of the RNA through the ring, followed by scanning via a one-dimensional search process, or sliding (Berg et al. 1981; Halford and Marko 2004). Accordingly, there are conserved residues in the Lsm and Sm rings, the latter of which have previously been observed to interact with "threaded" single stranded RNA (Supplemental Fig. 5).

\section{A model for Pat1 stimulation of RNA binding by Lsm1-7}

Taken together, our data suggest an allosteric model for Pat1-mediated stimulation of Lsm 1-7 binding (Chowdhury et al. 2014; Lobel et al. 2019). In this model, Pat1 binding displaces the Lsm1 carboxy-terminal domain to stimulate RNA binding affinity and relax specificity (Fig. 6). This model is consistent with existing structural data indicating that the carboxy-terminal domain of Pat1 binds to Lsm2 and Lsm3 (Sharif and Conti 2013; Wu et al. 2014), close to where the Lsm 1 carboxy-terminal helix reaches across to dock on the other side of the ring (Fig. 6A). This positioning would place the middle domain of Pat1, which is not present in the structure but is required for high affinity binding to oligoA RNA (Lobel et al. 2019), very close to the carboxy-terminal helix of Lsm1. Our model is also consistent with the observation that mutation of the Pat1 interaction surface with Lsm2-Lsm3 destroys the ability of Pat1 to stimulate the RNA-binding activity of $S$. pombe Lsm1-7 (Lobel et al. 2019) and leads to defects in mRNA degradation in S. cerevisiae (Sharif and Conti 2013; Wu et al. 2014). In S. cerevisiae, the carboxy-terminal alpha-helical extension of Lsm1 is required for high affinity binding to oligoA RNA in the presence of Pat1 (Chowdhury et al. 2012).

In summary, the Lsm proteins are essential RNA binding proteins that initiate the formation of molecular assemblies involved in major pathways of gene expression, including pre-mRNA splicing and mRNA decay. Understanding how these proteins recognize their RNA targets is therefore an important aspect of eukaryotic biology. We quantitatively demonstrate that the Lsm1-7 and Lsm2-8 complexes achieve strikingly different functional properties, despite similar quaternary structures and sharing of 
A

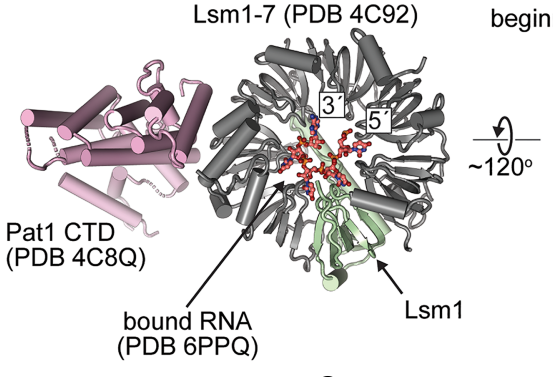

B

Lsm2-8 preferentially binds mature U6 snRNA tolerates adenylated RNA

C

Lsm1-7 discriminates against $>p$ RNA, prefers monopurinated RNAs Displacement of Lsm1
C-terminus allows Lsm1-7
to accomdate a broad

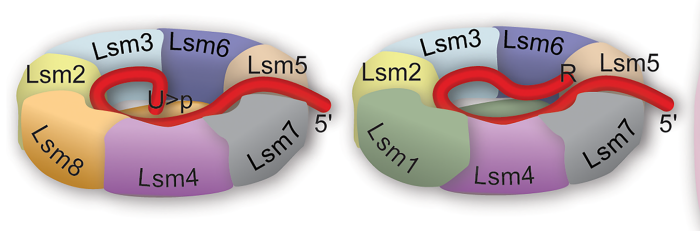

D range of RNAs
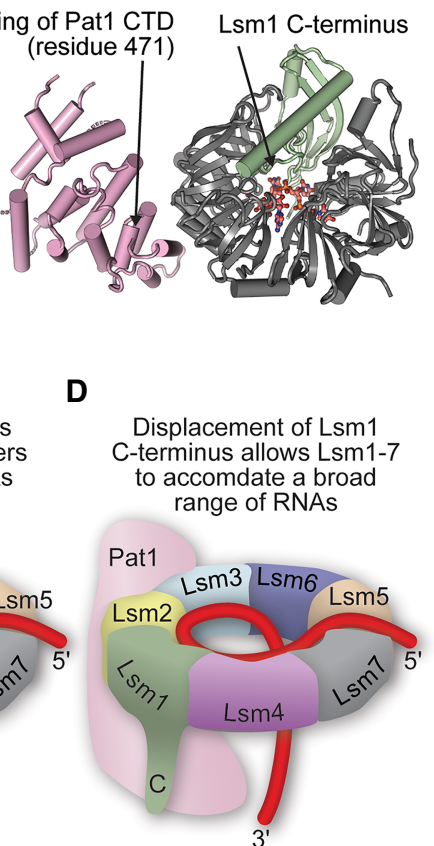

FIGURE 6. Proposed model for Pat1-regulated gating of the Lsm1-7 RNA-binding pore. (A) Relative orientations of RNA, Lsm1-7 and Pat1 proteins, derived from structures of $S$. pombe Lsm1-7 with RNA and S. cerevisiae Lsm1-7 with the carboxy-terminal domain of Pat1 (Sharif and Conti 2013). (B) Model for RNA binding specificity in Lsm rings. The Lsm2-8 ring contains a uridine-cyclic phosphate binding site that includes the carboxyl terminus of Lsm8 and endows specificity for Usb1 processed U6 snRNA. (C) In contrast, the carboxy-terminal region of Lsm1 in the Lsm1-7 ring antagonizes association of the ring with uridine-cyclic phosphate terminated RNA, while allowing association of the ring with $3^{\prime}$ monopurinated polyuridylate tracts. (D) Deletion of the carboxy-terminal region of $L s m 1$ allows the ring to associate with a broader range of RNAs. In vivo, the role of Lsm1 truncation may be mimicked by displacement of the carboxyl terminus by association of the ring with the Pat1 cofactor. It remains to be seen if RNA is capable of threading all the way through the pore of the RNA, as depicted here, or rather enters and exits the pore on the proximal face alone.

subunits. By elucidating the structures of these complexes bound to RNA, we establish the molecular basis for RNAprotein interactions that are fundamental to eukaryotic gene expression.

\section{MATERIALS AND METHODS}

\section{Production of recombinant Lsm2-8}

Codon optimized open reading frames (Genscript) for S. pombe Lsm proteins were cloned into modified variants of the pQLink expression system (Scheich et al. 2007). In the initial single open reading frame plasmids, Lsm2, Lsm5, and Lsm8 lacked purification tags. Lsm3 and Lsm6 harbored amino-terminal glutathione S-transferase and maltose-binding tags, respectively, with an intervening tobacco etch virus (TEV) protease site. Lsm4 and Lsm7 harbored noncleavable strep-II or hexahistidine tags, respectively, at their carboxy-termini. After cloning individual ORFs into individual plasmids, the multi-ORF expression system was assembled into a single plasmid through ligation independent cloning (Scheich et al. 2007) to yield a final plasmid with ORFs assembled in order Lsm6, Lsm3, Lsm2, Lsm8, Lsm4,

Lsm7, and Lsm5. The sequence of the final plasmid was confirmed by Sanger sequencing.

The resulting S. pombe Lsm2-8 expression plasmid was transformed into $E$. coli BL21(DE3) STAR pLysS cells (Invitrogen \# C602003). Cells were grown in terrific broth (RPI \# T15100-5000.0) containing ampicillin with shaking at $37^{\circ} \mathrm{C}$ until the $\mathrm{OD}_{600}$ was approximately 2 , at which point isopropyl $\quad \beta$-D-1-thiogalactopyranoside was added to a final concentration of $1 \mathrm{mM}$ and the cells were allowed to continue growing with shaking at $37^{\circ} \mathrm{C}$ for another $24 \mathrm{~h}$, at which point the $\mathrm{OD}_{600}$ was approximately 16 . Cells were harvested by centrifugation and the resulting cell pellet was resuspended in 0.025 volumes of buffer $A(500 \mathrm{mM} \mathrm{NaCl}, 50 \mathrm{mM}$ HEPES acid, $50 \mathrm{mM}$ imidazole base, 10\% glycerol, $1 \mathrm{mM}$ TCEP, final $\mathrm{pH} \sim 7$ ) per original volume of cell culture (i.e., 100 $\mathrm{mL}$ of resuspension buffer per $4 \mathrm{~L}$ of original cell culture). Protease inhibitors (EMD Millipore \# 539137-10VL) were added, as were DNase I (Sigma \# DN25-100MG) and lysozyme (Sigma \# 62971-10G-F) at a final concentration of 0.02 and $0.5 \mathrm{mg} /$ $\mathrm{mL}$, respectively. The resuspended cells were subjected to a single freeze-thaw cycle prior to sonication and clearance of cell debris by centrifugation.

The soluble fraction was first purified by immobilized metal affinity chromatography (Qiagen \# 30230) using gravity flow at room temperature. Buffer $A$ was used for washing and buffer A supplemented with $500 \mathrm{mM}$ imidazole $\mathrm{pH} \sim 7$ was used for step elution. The pooled eluate was then dialyzed overnight at $4^{\circ} \mathrm{C}$ with $20 \mathrm{kDa}$ MWCO membranes (Pierce \# 66012) into buffer B $(100 \mathrm{mM}$ $\mathrm{NaCl}, 10 \mathrm{mM}$ HEPES acid, $10 \mathrm{mM}$ sodium HEPES, 10\% glycerol, $1 \mathrm{mM}$ TCEP-HCl, $\mathrm{pH} \sim 7.0)$. Centrifugation was used to remove any precipitation that formed during dialysis. Soluble protein was further purified via glutathione agarose chromatography (GenScript \# L00206) with gravity flow at room temperature in fresh buffer B. Step elution was performed in buffer B supplemented with $50 \mathrm{mM}$ HEPES acid, $50 \mathrm{mM}$ sodium HEPES, and $10 \mathrm{mM}$ reduced glutathione. One milligram of TEV protease was added to the eluate, which was then dialyzed overnight as above, but at room temperature against $1 \mathrm{~L}$ of buffer $\mathrm{C}$ (150 mM NaCl, $50 \mathrm{mM}$ tris base, $50 \mathrm{mM}$ tris- $\mathrm{HCl}, 1 \mathrm{mM}$ trisodium EDTA, $1 \mathrm{mM}$ TCEP-HCl, $1 \mathrm{mM}$ sodium azide, $\mathrm{pH} \sim 8.0$ ). Dialyzed protein was then purified using gravity flow chromatography at room temperature on Strep-Tactin agarose (IBA GmBH \# 21208-025) in fresh buffer $C$, with step elution in buffer $C$ supplemented with $2.5 \mathrm{mM}$ biotin. The resulting eluate was manually applied at room temperature to a $1 \mathrm{~mL}$ HiTrapQ anion exchange column (GE Healthcare \# 29051325) that had been preequilibrated in buffer B. The column was then attached to an AKTA chromatography system at $4^{\circ} \mathrm{C}$ and elution accomplished by applying a linear gradient of $\mathrm{NaCl}$ up to $2 \mathrm{M}$ in buffer $\mathrm{B}$. The Lsm2-8 
complex desorbed from the column at $\sim 250 \mathrm{mM} \mathrm{NaCl}$. Peak fractions were collected, pooled, and the concentration of the purified complex was determined by UV absorbance and the estimated molar extinction coefficient of $46,300 \mathrm{M}^{-1} \mathrm{~cm}^{-1}$ at $280 \mathrm{~nm}$ (Wilkins et al. 1999). Final purity of the Lsm2-8 complex was determined by $20 \%$ (29:1) tris-tricine SDS-PAGE. The presence of all protein components was further confirmed by electrospray ionization mass spectrometry at the UW-Madison Biotechnology Center Mass Spectrometry Facility, where the amino-terminal methionine of Lsm5 and Lsm8 was found to be missing, and Lsm7 lacked either 1 or 2 amino-terminal residues. Protein samples were either stored at $4^{\circ} \mathrm{C}$ or frozen as $100 \mu \mathrm{L}$ aliquots in liquid nitrogen before long-term storage at $-80^{\circ} \mathrm{C}$.

\section{Production of recombinant Lsm1-7}

The Lsm1-7 complex was produced as described for Lsm2-8, with the following exceptions. The multi-ORF expression system was assembled into a single plasmid through ligation independent cloning as described for Lsm2-8, with the ORFs assembled in order Lsm6, Lsm3, Lsm2, Lsm1, Lsm4, Lsm7, and Lsm5. Lsm7 lacked a purification tag.

Protein expression, purification and storage were performed as with the above Lsm2-8 complex, with the exception that StrepTactin chromatography was not used and instead the eluate from glutathione agarose chromatography was loaded directly onto a HiTrapQ column after overnight incubation with TEV protease at room temperature. Peak fractions were collected, pooled, and the concentration of the purified complex was determined by UV absorbance and the estimated molar extinction coefficient at $280 \mathrm{~nm}$ (Wilkins et al. 1999). Electrospray ionization mass spectrometry showed that all protein chains were full-length with the exception of Lsm5 and Lsm7, which lacked 1 and 1-2 residues from their amino-termini, respectively.

In order to prepare the Lsm5-N66A/N68A or Lsm1 carboxy-terminal truncation mutants of Lsm1-7, a modified inverse PCR mutagenesis protocol was used on the multi-ORF Lsm1-7 expression plasmid. PCR amplification was performed in "GC" optimized Pfusion buffer (NEB \# M0532S) using a gradient of annealing temperatures and oligonucleotides that anneal only within the unique open reading frame regions of each Lsm locus. Amplicons of correct length were gel purified prior to phosphorylation and ligation. All mutant clones were confirmed to be of correct length and sequence by analytical restriction enzyme digestion and Sanger sequencing.

\section{Production of recombinant Prp24}

A codon optimized open reading frame (Genscript) for S. pombe Prp24 was cloned into a modified variant of plasmid pET3a, encoding an octahistidine tag, biotin acceptor peptide sequence (Beckett et al. 1999), and tobacco etch virus (TEV) protease site located upstream of the Prp24 ORF. The sequence of the final plasmid was confirmed by Sanger sequencing.

The S. pombe Prp24 was produced as described above for the Lsm proteins with the following exceptions. Cells were harvested by centrifugation and the resulting cell pellet was resuspended in 0.1 volumes of buffer $\mathrm{A}(500 \mathrm{mM} \mathrm{NaCl}, 50 \mathrm{mM}$ HEPES acid, $50 \mathrm{mM}$ imidazole base, $10 \%$ glycerol, $1 \mathrm{mM}$ TCEP, final $\mathrm{pH} \sim 7$ ) per original volume of cell culture (i.e., $100 \mathrm{~mL}$ of resuspension buffer per $1 \mathrm{~L}$ of original cell culture).

Soluble protein was manually applied at room temperature to a $5 \mathrm{~mL}$ HiTrapO anion exchange column (GE Healthcare \# 29051325) that had been preequilibrated in buffer $B$. The column was then attached to an AKTA chromatography system at $4^{\circ} \mathrm{C}$ and elution accomplished by applying a linear gradient of $\mathrm{NaCl}$ up to $2 \mathrm{M}$ in buffer $\mathrm{B}$. The peak fractions were collected, pooled, diluted twofold against fresh buffer $B$ and then manually applied at room temperature to a $5 \mathrm{~mL}$ HiTrap Heparin cation exchange column (GE Healthcare \# 17040701) that had been preequilibrated in buffer $\mathrm{B}$. The column was then attached to an AKTA chromatography system at $4^{\circ} \mathrm{C}$ and elution accomplished by applying a linear gradient of $\mathrm{NaCl}$ up to $2 \mathrm{M}$ in buffer $\mathrm{B}$. The peak fractions were pooled and the final concentration of protein was determined by UV absorbance and the estimated molar extinction coefficient of $114,600 \mathrm{M}^{-1} \mathrm{~cm}^{-1}$ at $280 \mathrm{~nm}$ (Wilkins et al. 1999). Protein samples at $\sim 6 \mathrm{mg} / \mathrm{mL}$ were either stored at $4^{\circ} \mathrm{C}$, or frozen as $100 \mu \mathrm{L}$ aliquots in liquid nitrogen before long-term storage at $-80^{\circ} \mathrm{C}$.

\section{Synthesis and purification of RNA}

In vitro transcription with T7 RNA polymerase was used to synthesize mature S. pombe U6 nucleotides 1-100 (Tani and Ohshima 1989) from a linearized pUC57 plasmid template harboring a T7 promoter (TTCTAATACGACTCACTATA) and a minimal 56 nucleotide HDV ribozyme "drz-Mtgn-3" (Riccitelli et al. 2014) to ensure a homogenous $3^{\prime}$ end with a cyclic phosphate. A $20 \mathrm{~mL}$ transcription reaction contained $\sim 0.25 \mathrm{mg} / \mathrm{mL}$ linearized plasmid template, $\sim 0.5 \mathrm{mg} / \mathrm{mL}$ T7 RNA polymerase, $5 \mathrm{mM}$ each of ATP, GTP, CTP and UTP; $100 \mathrm{mM}$ tris, $100 \mathrm{mM}$ Tris- $\mathrm{HCl}, 40 \mathrm{mM}$ $\mathrm{MgCl}_{2}, 5 \mathrm{mM}$ DTT, $1 \mathrm{mM}$ spermidine trihydrochloride, and $0.01 \%(v / v)$ Triton X-100. Synthesis of RNA was performed at $37^{\circ} \mathrm{C}$ for $2 \mathrm{~h}$. Trisodium EDTA pH 8.0 was then added to a final concentration of $100 \mathrm{mM}$ to halt transcription and solubilize accumulated magnesium pyrophosphate. The transcription was then concentrated to $\sim 400 \mu \mathrm{L}$ with $10 \mathrm{kDa}$ MWCO spin filters (Amicon \# UFC901008) prior to addition of $6 \mathrm{~mL}$ of $100 \%$ formamide and subsequent electrophoresis on a denaturing 10\% (19:1) polyacrylamide gel containing containing $8 \mathrm{M}$ urea, $100 \mathrm{mM}$ tris base, $100 \mathrm{mM}$ boric acid, and $1 \mathrm{mM}$ EDTA acid. Full-length U6 RNA was identified by UV shadowing, extracted by scalpel, and removed from the gel matrix by passive diffusion overnight at room temperature with gently shaking into a solution containing $300 \mathrm{mM}$ sodium acetate, $50 \mathrm{mM} \mathrm{HCl}, 1 \mathrm{mM}$ EDTA, $1 \mathrm{mM}$ sodium azide, $\mathrm{pH} \sim 5$.6. Soluble RNA was separated from solid acrylamide by filtration through 0.22 micron filters and then manually applied to a $5 \mathrm{~mL}$ HiTrap Q column (GE Healthcare \# 29051325) that had been equilibrated in buffer $\mathrm{D}\left(300 \mathrm{mM} \mathrm{NaCl}, 10 \mathrm{mM} \mathrm{KH}_{2} \mathrm{PO}_{4}\right.$, $10 \mathrm{mM} \mathrm{K}_{2} \mathrm{HPO}_{4}, 1 \mathrm{mM}$ EDTA acid, $1 \mathrm{mM}$ sodium azide, $\mathrm{pH} \sim 7$ ). Bound RNA was washed with $20 \mathrm{~mL}$ of buffer $D$ and then eluted in a single step with buffer $\mathrm{D}$ adjusted to $2 \mathrm{M} \mathrm{NaCl}$. Eluted RNA was pooled and concentration and buffer exchange were accomplished by three iterations of 10-fold concentration (Amicon \# UFC501008) and redilution against buffer $\mathrm{E}(100 \mathrm{mM} \mathrm{KCl}$, $20 \mathrm{mM}$ bis-tris, $10 \mathrm{mM} \mathrm{HCl}, 1 \mathrm{mM}$ EDTA, $1 \mathrm{mM}$ sodium azide, $\mathrm{pH} \sim 6.5)$. The final RNA concentration was estimated using UV absorption and an anticipated extinction coefficient of $1,223,990 \mathrm{M}^{-1} \mathrm{~cm}^{-1}$ at $260 \mathrm{~nm}$ (Kibbe 2007). 
In order to generate a pentauridylate RNA with a 3' cyclic phosphate for cocrystallization with S. pombe Lsm2-8, an RNA oligo with sequence $5^{\prime}$-UUUUUA-3' was purchased from Integrated DNA Technologies (IDT) and treated with human Usb1, which rapidly removes $3^{\prime}$ adenosine residues from oligoU tracts and leaves a $3^{\prime}$ cyclic phosphate that is not subjected to ring opening as with S. cerevisiae Usb1 (Didychuk et al. 2017; Nomura et al. 2018). Human Usb1 was prepared exactly as described elsewhere (Nomura et al. 2018). The conversion protocol involved resuspension of an RNA pellet from IDT in buffer $E$ to a final concentration of $2.7 \mathrm{mM}$. A limiting amount of enzyme was used to ensure the product RNA was predominantly that of a single cleavage reaction. This was accomplished by adding $180 \mu \mathrm{L}$ of RNA at $2.7 \mathrm{mM}$ to $180 \mu \mathrm{L}$ of human Usb1 at $32 \mu \mathrm{M}$ in buffer $\mathrm{F}(100 \mathrm{mM}$ $\mathrm{NaCl}, 10 \mathrm{mM}$ HEPES acid, $10 \mathrm{mM}$ sodium HEPES base, $40 \%$ glycerol, $1 \mathrm{mM}$ TCEP-HCl, $1 \mathrm{mM}$ trisodium EDTA, $\mathrm{pH} \sim 7$ ) and incubation at $37^{\circ} \mathrm{C}$ for $1 \mathrm{~h}$. The RNA was purified by $20 \%$ polyacrylamide denaturing gel electrophoresis and anion exchange chromatography as above, with the exception that HiTrapQ wash buffer contained $100 \mathrm{mM} \mathrm{NaCl}, 10 \mathrm{mM}$ HEPES acid, and $10 \mathrm{mM}$ sodium HEPES base, and the step elution buffer contained $1 \mathrm{M}$ instead of $2 \mathrm{M} \mathrm{NaCl}$. The eluted RNA was pooled and not subsequently adjusted prior to addition to Lsm2-8 (see below). The concentration of RNA was determined using an approximate molar extinction coefficient of $50,000 \mathrm{M}^{-1} \mathrm{~cm}^{-1}$ at $260 \mathrm{~nm}$ (Kibbe 2007). All other RNAs used for cocrystallization experiments were purchased from IDT and resuspended in buffer $E$ without further modification prior to addition to protein (see below).

The 5'-FAM labeled RNAs used for fluorescence polarization (S. pombe U6 nucleotides 91-100 and similar) were purchased from Integrated DNA Technologies and purified by urea PAGE and ion exchange as above for full-length U6, with the following exceptions: UV shadowing was not used (or required) to visualize the RNA after denaturing electrophoresis, concentration of RNA after anion-exchange chromatography was performed with $3 \mathrm{kDa}$ MWCO spin filters (Amicon \# UFC500308), and the final RNA concentration was estimated using UV absorption and an anticipated extinction coefficient of 75,000 $\mathrm{M}^{-1} \mathrm{~cm}^{-1}$ at $495 \mathrm{~nm}$ (Kibbe 2007). In the case of the cyclic phosphate probe, a limiting amount of human Usb1 was added to an adenosine terminated RNA as above.

\section{Fluorescence polarization binding assays}

All fluorescence polarization binding assays were performed in buffer $\mathrm{H}(100 \mathrm{mM} \mathrm{NaCl}, 20 \mathrm{mM}$ tris $\mathrm{pH}$ 8.2, $10 \mathrm{mM} \mathrm{MgCl}$, $1 \mathrm{mM}$ TCEP HCl, $1 \mathrm{mM}$ sodium azide, $0.1 \mathrm{mg} / \mathrm{mL}$ tRNA [Roche \# 12172120], $0.1 \mathrm{mg} / \mathrm{mL}$ BSA [Ambion \# AM2616], and $0.1 \mathrm{mg} /$ $\mathrm{mL}$ sodium heparin [Sigma \# N4784-250MG], pH 8) in black 96 well microplates (Greiner Bio-One \# 655209) and imaged on a Tecan Infinite M1000Pro using an excitation wavelength of $470 \mathrm{~nm}$ and emission wavelength of $519 \mathrm{~nm}$. For each sample, $100 \mu \mathrm{L}$ of RNA at $2 \mathrm{nM}$ was added to $100 \mu \mathrm{L}$ of protein at a defined concentration between $0.4 \mathrm{nM}$ and $5 \mu \mathrm{M}$. Fluorescence polarization was measured in duplicate from two independent titrations using different protein concentrations. Binding curves were fit using nonlinear regression in GraphPad Prism 4 to the following four parameter equation: $F P=F P_{\text {min }}+\left(F P_{\text {max }}-F P_{\text {min }}\right) /$ $\left(1+10 \wedge\left(\left(\log K_{d}-\log [\text { protein] })^{*} H\right)\right)\right.$, where $F P_{\min }$ and $F P_{\text {max }}$ are the minimum and maximum polarizations, $K_{d}$ is the binding disso- ciation constant, and $\mathrm{H}$ is the Hill coefficient. $\mathrm{H}$ was constrained to be 1 during nonlinear regression. Depicted binding curves are normalized to $\mathrm{FP}_{\min }$ and $\mathrm{FP}_{\max }$. All raw binding data are provided in Supplemental Data File 1.

\section{Crystallization and structure determination of Lsm2-8 complexes}

The Lsm2-8/RNA complexes were reconstituted by adding crude RNA from IDT to protein in an approximately twofold stoichiometric excess. The complexes were then dialyzed overnight at $4^{\circ} \mathrm{C}$ against $1 \mathrm{~L}$ of buffer I $(50 \mathrm{mM} \mathrm{NaCl}, 10 \mathrm{mM} \mathrm{MgCl}, 10 \mathrm{mM}$ tris- $\mathrm{HCl}, 10 \mathrm{mM}$ bis-tris base, $1 \mathrm{mM}$ TCEP-HCl, $\mathrm{pH} \sim 7$ ) using 20 kDa MWCO membranes (Pierce \# 66012). The dialyzed complexes were concentrated to $\sim 10 \mathrm{mg} / \mathrm{mL}$ with $50 \mathrm{kDa}$ MWCO spin filters (Amicon \# UFC505008) prior to high-throughput crystallization screening on a Mosquito crystallization robot (TTP Labtech). Initial crystallization hits were obtained exclusively using the precipitant pentaerythritol propoxylate $(5 / 4 \mathrm{PO} / \mathrm{OH})$ in a MIDAS screen (Molecular Dimensions \# MD1-59). Crystals were optimized by hanging drop vapor diffusion at $16^{\circ} \mathrm{C}$, using $2 \mu \mathrm{L}$ of Lsm2-8/RNA complexes mixed with $2 \mu \mathrm{L}$ of crystallization reagent containing 100-200 mM KCl, 50-100 mM HEPES pH 7.4, 35\% pentaerythritol propoxylate $(5 / 4 \mathrm{PO} / \mathrm{OH})$. Crystals were vitrified by direct immersion into liquid nitrogen.

Diffraction data were integrated using XDS (Kabsch 2010). Space group determination was performed in POINTLESS (Evans 2011). STARANISO (Tickle et al. 2017) was used for merging and ellipsoidal truncation of the anisotropic diffraction data. Phenix.xtriage was used to assay potential twinning in the diffraction data (Adams et al. 2010). Initial phases were determined by molecular replacement using Phaser (McCoy et al. 2007).

For the $3^{\prime}$ diol terminated structure (PDB 6PPN), three diffraction data sets were collected from two isomorphous crystals at $100 \mathrm{~K}$ on beamline 24-ID-E at the Advanced Photon Source. Molecular replacement was used to obtain initial phases with initial search templates PDB 4EMG (S. pombe Lsm3) (Wu et al. 2012), PDB 4EMH (S. pombe Lsm4) (Wu et al. 2012), PDB 4EMK (S. pombe Lsm5/6/7) (Wu et al. 2012), and homology models (Marti-Renom et al. 2000; Zimmermann et al. 2018) of S. pombe Lsm2 and Lsm8 that were constructed from the corresponding S. cerevisiae orthologs (PDB 4C92 and 4M7D, respectively) (Sharif and Conti 2013; Zhou et al. 2014a). Molecular replacement used a single search model in which the above seven proteins were placed in a fixed orientation relative to one another to resemble the known architecture of the $S$. cerevisiae Lsm rings (Sharif and Conti 2013; Zhou et al. 2014a; Montemayor et al. 2018). Structure refinement was performed in Phenix.refine (Adams et al. 2010; Afonine et al. 2012) using secondary structure restraints and TLS parameterization, with iterative rounds of manual model building in Coot (Emsley and Cowtan 2004; Emsley et al. 2010) and additional automated refinement in Phenix.refine.

The 2', $3^{\prime}$-cyclic phosphate terminated structure (PDB 6PPP) was determined as above, but using addition of a different RNA prior to dialysis and using the above S. pombe Lsm2-8 structure for molecular replacement. Twelve diffraction data sets were collected from two isomorphous crystals at $100 \mathrm{~K}$ on beamline 21-ID-D at the Advanced Photon Source. Structure refinement was performed in Phenix.refine (Adams et al. 2010; Afonine et al. 2012) 
using secondary structure restraints and TLS parameterization, in combination with reference model restraints to the best resolved Lsm2-8 ring in PDB 6PPN.

\section{Crystallization and structure determination of Lsm1-7 complexes}

Schizosaccharomyces pombe Lsm1-7 complexes lacking the carboxy-terminal 56 residues of Lsm1 were reconstituted with RNA as above, adding 5'-UUUUUA-3' for PDB 6PPO or 5'-AUUUUG$3^{\prime}$ for PDB 6PPV. Crystals were obtained by mixing $0.2 \mu \mathrm{L}$ of complex with $0.2 \mu \mathrm{L}$ of the following mixture: $20 \mathrm{mM}$ sodium formate, $20 \mathrm{mM}$ ammonium acetate, $20 \mathrm{mM}$ trisodium citrate, $20 \mathrm{mM}$ sodium potassium tartrate, $20 \mathrm{mM}$ sodium oxamate, $100 \mathrm{mM}$ sodium HEPES base, 100 mM MOPS acid, 10\% PEG 8000, and $20 \%$ ethylene glycol. Crystals were vitrified by direct immersion into liquid nitrogen.

The $3^{\prime}$ adenosine terminated structure (PDB 6PPQ) was determined by merging three diffraction data sets collected from a single crystal at $100 \mathrm{~K}$ on beamline 21-ID-D at the Advanced Photon Source. PDB 6PPN was used for molecular replacement. Structure refinement was performed in Phenix.refine (Adams et al. 2010; Afonine et al. 2012) using secondary structure restraints. The $3^{\prime}$ adenosine binding pocket was first identified by residual FoFc density after modeling and refining tetrauridylate into the four typical Sm-like pockets in Lsm1-7. Subsequent to incorporating the $3^{\prime}$ adenosine, the final electron density maps exhibited residual Fo-Fc density that could not be remediated by deletion of the adenosine or changing the identity of the adenosine to uridine. We therefore conclude the remaining Fo-Fc density is due to unmodeled dynamics in the $3^{\prime}$ adenosine binding pocket.

The $3^{\prime}$ guanosine terminated structure (PDB 6PPV) was determined from a single diffraction data set collected from a single crystal at $100 \mathrm{~K}$ on beamline 21-ID-D at the Advanced Photon Source. PDB 6PPQ was used for molecular replacement and refinement was conducted as above. The $3^{\prime}$ guanosine binding pocket did not exhibit residual Fo-Fc density as above for adenosine.

For all structures presented here, simulated annealing omit maps were prepared to confirm the presence of bound RNA in the final models deposited into the Protein Data Bank. All figures were generated with PyMOL (http://www.pymol.org). Structural biology applications used in this project were compiled and configured by SBGrid (Morin et al. 2013). Electrostatic surface potentials were calculated using APBS (Baker et al. 2001) as implemented in PyMOL. All final coordinate sets and structure factors with calculated phases are provided in Supplemental Data File 2. A PyMol session with annotation matching that used throughout the manuscript is provided as Supplemental Data File 3.

\section{SUPPLEMENTAL MATERIAL}

Supplemental material is available for this article.

\section{ACKNOWLEDGMENTS}

We are grateful to Aaron Hoskins, members of the Brow and Butcher laboratories, Elsebet Lund and Stephen Floor for helpful discussions and critical reading of the manuscript, and Laura Vanderploeg for illustrations. Use of the Advanced Photon Source, an Office of Science User Facility operated for the U.S. Department of Energy (DOE) Office of Science by Argonne National Laboratory, was supported by the U.S. DOE under contract no. DE-AC02-06CH11357. Use of NE-CAT was supported by the National Institutes of Health (NIH) grants P41 GM103403 and S10 RR029205. Use of LS-CAT was supported by NIH grant 085P1000817. This project has been funded in whole or in part with federal funds from the National Cancer Institute, National Institutes of Health, under contract HHSN26120080001E. This research used 12-ID-B beamline of the Advanced Photon Source, a U.S. Department of Energy (DOE) Office of Science User Facility operated for the DOE Office of Science by Argonne National Laboratory under contract no. DE-AC02-06CH11357. Fluorescence polarization data were obtained at the University of Wisconsin-Madison Biophysics Instrumentation Facility, which was established with support from the University of Wisconsin-Madison and grants BIR-9512577 (National Science Foundation) and S10RR13790 (NIH). This study was supported by NIH grants R35 GM118075 to D.A.B. and R35 GM118131 to S.E.B.

Author contributions: E.J.M., J.M.V., S.M.H., and Y.N. prepared reagents. E.J.M. collected diffraction data and determined the crystal structures. E.J.M. and J.M.V. performed in vitro binding assays. E.J.M. and S.E.B. supervised the work. E.J.M., D.A.B., and S.E.B. wrote the manuscript.

Received April 12, 2020; accepted June 3, 2020.

\section{REFERENCES}

Adams PD, Afonine PV, Bunkoczi G, Chen VB, Davis IW, Echols N, Headd JJ, Hung LW, Kapral GJ, Grosse-Kunstleve RW, et al. 2010. PHENIX: a comprehensive Python-based system for macromolecular structure solution. Acta Crystallogr D Biol Crystallogr 66: 213-221. doi:10.1107/S0907444909052925

Afonine PV, Grosse-Kunstleve RW, Echols N, Headd JJ, Moriarty NW, Mustyakimov M, Terwilliger TC, Urzhumtsev A, Zwart PH, Adams PD. 2012. Towards automated crystallographic structure refinement with phenix.refine. Acta Crystallogr D Biol Crystallogr 68: 352-367. doi:10.1107/S0907444912001308

Agafonov DE, Kastner B, Dybkov O, Hofele RV, Liu WT, Urlaub H, Luhrmann R, Stark H. 2016. Molecular architecture of the human U4/U6.U5 tri-snRNP. Science 351: 1416-1420. doi:10.1126/sci ence.aad2085

Baker NA, Sept D, Joseph S, Holst MJ, McCammon JA. 2001. Electrostatics of nanosystems: application to microtubules and the ribosome. Proc Natl Acad Sci 98: 10037-10041. doi:10 $.1073 /$ pnas. 181342398

Barreau C, Paillard L, Osborne HB. 2005. AU-rich elements and associated factors: are there unifying principles? Nucleic Acids Res 33: 7138-7150. doi:10.1093/nar/gki1012

Beckett D, Kovaleva E, Schatz PJ. 1999. A minimal peptide substrate in biotin holoenzyme synthetase-catalyzed biotinylation. Protein Sci 8: 921-929. doi:10.1110/ps.8.4.921

Berg OG, Winter RB, von Hippel PH. 1981. Diffusion-driven mechanisms of protein translocation on nucleic acids. 1. Models and theory. Biochemistry 20: 6929-6948. doi:10.1021/bi00527a028

Bouveret E, Rigaut G, Shevchenko A, Wilm M, Seraphin B. 2000. A $\mathrm{Sm}$-like protein complex that participates in mRNA degradation. EMBO J 19: 1661-1671. doi:10.1093/emboj/19.7.1661 
Charenton C, Wilkinson ME, Nagai K. 2019. Mechanism of $5^{\prime}$ splice site transfer for human spliceosome activation. Science 364: 362-367. doi:10.1126/science.aax3289

Chowdhury A, Mukhopadhyay J, Tharun S. 2007. The decapping activator Lsm 1p-7p-Pat1p complex has the intrinsic ability to distinguish between oligoadenylated and polyadenylated RNAs. RNA 13: 998-1016. doi:10.1261/rna.502507

Chowdhury A, Raju KK, Kalurupalle S, Tharun S. 2012. Both Smdomain and C-terminal extension of Lsm1 are important for the RNA-binding activity of the Lsm1-7-Pat1 complex. RNA 18: 936944. doi:10.1261/rna.029876.111

Chowdhury A, Kalurupalle S, Tharun S. 2014. Pat1 contributes to the RNA binding activity of the Lsm1-7-Pat1 complex. RNA 20: 14651475. doi:10.1261/rna.045252.114

Decker CJ, Teixeira D, Parker R. 2007. Edc3p and a glutamine/asparagine-rich domain of Lsm4p function in processing body assembly in Saccharomyces cerevisiae. J Cell Biol 179: 437-449. doi:10 $.1083 / j c b .200704147$

Didychuk AL, Montemayor EJ, Carrocci TJ, DeLaitsch AT, Lucarelli SE، Westler WM, Brow DA, Hoskins AA, Butcher SE. 2017. Usb1 controls U6 snRNP assembly through evolutionarily divergent cyclic phosphodiesterase activities. Nat Commun 8: 497. doi:10.1038/ s41467-017-00484-w

Didychuk AL, Butcher SE, Brow DA. 2018. The life of U6 small nuclear RNA, from cradle to grave. RNA 24: 437-460. doi:10.1261/rna .065136 .117

Dominski Z, Marzluff WF. 2007. Formation of the $3^{\prime}$ end of histone mRNA: getting closer to the end. Gene 396: 373-390. doi:10 .1016/j.gene.2007.04.021

Emsley P, Cowtan K. 2004. Coot: model-building tools for molecular graphics. Acta Crystallogr D Biol Crystallogr 60: 2126-2132. doi:10.1107/S0907444904019158

Emsley P, Lohkamp B, Scott WG, Cowtan K. 2010. Features and development of Coot. Acta Crystallogr D Biol Crystallogr 66: 486-501. doi:10.1107/S0907444910007493

Evans PR. 2011. An introduction to data reduction: space-group determination, scaling and intensity statistics. Acta Crystallogr D Biol Crystallogr 67: 282-292. doi:10.1107/S090744491003982X

Galao RP, Chari A, Alves-Rodrigues I, Lobao D, Mas A, Kambach C, Fischer U, Diez J. 2010. LSm1-7 complexes bind to specific sites in viral RNA genomes and regulate their translation and replication. RNA 16: 817-827. doi:10.1261/rna.1712910

Garre E, Pelechano V, Sanchez Del Pino M, Alepuz P, Sunnerhagen P. 2018. The Lsm1-7/Pat1 complex binds to stress-activated mRNAs and modulates the response to hyperosmotic shock. PLoS Genet 14: e1007563. doi:10.1371/journal.pgen.1007563

Gatica D, Hu G, Liu X, Zhang N, Williamson PR, Klionsky DJ. 2019. The Pat1-Lsm complex stabilizes ATG mRNA during nitrogen starvation-induced autophagy. Mol Cell 73: 314-324.e4. doi:10.1016/j .molcel.2018.11.002

Grabarkiewicz T, Hoffmann M. 2006. Syn- and anti-conformations of 5'-deoxy- and 5'-O-methyl-uridine 2', 3'-cyclic monophosphate. J Mol Model 12: 205-212. doi:10.1007/s00894-005-0019-5

Halford SE, Marko JF. 2004. How do site-specific DNA-binding proteins find their targets? Nucleic Acids Res 32: 3040-3052. doi:10 .1093/nar/gkh624

He W, Parker R. 2001. The yeast cytoplasmic Lsml/Pat1p complex protects mRNA $3^{\prime}$ termini from partial degradation. Genetics 158: 1445-1455.

Hilcenko C, Simpson PJ, Finch AJ, Bowler FR, Churcher MJ, Jin L, Packman LC, Shlien A, Campbell P, Kirwan M, et al. 2013. Aberrant $3^{\prime}$ oligoadenylation of spliceosomal U6 small nuclear RNA in poikiloderma with neutropenia. Blood 121: 1028-1038. doi:10.1182/blood-2012-10-461491
Jungfleisch J, Chowdhury A, Alves-Rodrigues I, Tharun S, Diez J. 2015. The Lsm1-7-Pat1 complex promotes viral RNA translation and replication by differential mechanisms. RNA 21: 1469-1479. doi:10.1261/rna.052209.115

Kabsch W. 2010. XDS. Acta Crystallogr D Biol Crystallogr 66: 125132. doi:10.1107/S0907444909047337

Kibbe WA. 2007. OligoCalc: an online oligonucleotide properties calculator. Nucleic Acids Res 35: W43-W46. doi:10.1093/nar/ gkm234

Kufel J, Bousquet-Antonelli C, Beggs JD, Tollervey D. 2004. Nuclear pre-mRNA decapping and $5^{\prime}$ degradation in yeast require the Lsm2-8p complex. Mol Cell Biol 24: 9646-9657. doi:10.1128/ MCB.24.21.9646-9657.2004

Lerner MR, Steitz JA. 1979. Antibodies to small nuclear RNAs complexed with proteins are produced by patients with systemic lupus erythematosus. Proc Natl Acad Sci 76: 5495-5499. doi:10.1073/ pnas.76.11.5495

Leung AK, Nagai K, Li J. 2011. Structure of the spliceosomal U4 snRNP core domain and its implication for snRNP biogenesis. Nature 473: 536-539. doi:10.1038/nature09956

Li J, Leung AK, Kondo Y, Oubridge C, Nagai K. 2016. Re-refinement of the spliceosomal U4 snRNP core-domain structure. Acta Crystallogr D Struct Biol 72: 131-146. doi:10.1107/S2059798 315022111

Lin WJ, Duffy A, Chen CY. 2007. Localization of AU-rich element-containing mRNA in cytoplasmic granules containing exosome subunits. J Biol Chem 282: 19958-19968. doi:10.1074/jbc M702281200

Lobel JH, Tibble RW, Gross JD. 2019. Pat1 activates late steps in mRNA decay by multiple mechanisms. Proc Natl Acad Sci 116: 23512-23517. doi:10.1073/pnas. 1905455116

Lund E, Dahlberg JE. 1992. Cyclic 2',3'-phosphates and nontemplated nucleotides at the $3^{\prime}$ end of spliceosomal U6 small nuclear RNA's. Science 255: 327-330. doi:10.1126/science.1549778

Lyons SM, Ricciardi AS, Guo AY, Kambach C, Marzluff WF. 2014. The C-terminal extension of Lsm4 interacts directly with the $3^{\prime}$ end of the histone $\mathrm{mRNP}$ and is required for efficient histone mRNA degradation. RNA 20: 88-102. doi:10.1261/rna.042531.113

Marti-Renom MA, Stuart AC, Fiser A, Sanchez R, Melo F, Sali A. 2000. Comparative protein structure modeling of genes and genomes. Annu Rev Bioph Biom 29: 291-325. doi:10.1146/annurev .biophys.29.1.291

Mayes AE, Verdone L, Legrain P, Beggs JD. 1999. Characterization of $\mathrm{Sm}$-like proteins in yeast and their association with U6 snRNA. EMBO J 18: 4321-4331. doi:10.1093/emboj/18.15.4321

McCoy AJ, Grosse-Kunstleve RW, Adams PD, Winn MD, Storoni LC, Read RJ. 2007. Phaser crystallographic software. J Appl Crystallogr 40: 658-674. doi:10.1107/S0021889807021206

Montemayor EJ, Didychuk AL, Yake AD, Sidhu GK, Brow DA, Butcher SE. 2018. Architecture of the U6 snRNP reveals specific recognition of $3^{\prime}$-end processed U6 snRNA. Nat Commun 9: 1749. doi:10.1038/s41467-018-04145-4

Moore MJ. 2005. From birth to death: the complex lives of eukaryotic mRNAs. Science 309: 1514-1518. doi:10.1126/science.1111443

Morin A, Eisenbraun B, Key J, Sanschagrin PC, Timony MA, Ottaviano M, Sliz P. 2013. Collaboration gets the most out of software. Elife 2: e01456. doi:10.7554/eLife.01456

Mugridge JS, Tibble RW, Ziemniak M, Jemielity J, Gross JD. 2018. Structure of the activated Edc1-Dcp1-Dcp2-Edc3 mRNA decapping complex with substrate analog poised for catalysis. Nat Commun 9: 1152. doi:10.1038/s41467-018-03536-x

Mura C, Randolph PS, Patterson J, Cozen AE. 2013. Archaeal and eukaryotic homologs of $\mathrm{Hfq}$ : a structural and evolutionary perspective on Sm function. RNA Biol 10: 636-651. doi:10.4161/rna .24538 
Nomura Y, Roston D, Montemayor EJ, Cui Q, Butcher SE. 2018. Structural and mechanistic basis for preferential deadenylation of U6 snRNA by Usb1. Nucleic Acids Res 46: 11488-11501. doi:10 $.1093 /$ nar/gky812

Parker R. 2012. RNA degradation in Saccharomyces cerevisae. Genetics 191: 671-702. doi:10.1534/genetics.111.137265

Reijns MA, Alexander RD, Spiller MP, Beggs JD. 2008. A role for Q/Nrich aggregation-prone regions in P-body localization. J Cell Sci 121: 2463-2472. doi:10.1242/jcs.024976

Reijns MA, Auchynnikava T, Beggs JD. 2009. Analysis of Lsm1p and Lsm8p domains in the cellular localization of Lsm complexes in budding yeast. FEBS J 276: 3602-3617. doi:10.1111/j.17424658.2009.07080.x

Riccitelli NJ, Delwart E, Luptak A. 2014. Identification of minimal HDVlike ribozymes with unique divalent metal ion dependence in the human microbiome. Biochemistry 53: 1616-1626. doi:10.1021/ bi401717w

Scheich C, Kummel D, Soumailakakis D, Heinemann U, Bussow K. 2007. Vectors for co-expression of an unrestricted number of proteins. Nucleic Acids Res 35: e43. doi:10.1093/nar/gkm067

Sharif H, Conti E. 2013. Architecture of the Lsm1-7-Pat1 complex: a conserved assembly in eukaryotic mRNA turnover. Cell Rep 5: 283-291. doi:10.1016/j.celrep.2013.10.004

Shigematsu M, Kawamura T, Kirino Y. 2018. Generation of 2', 3'-cyclic phosphate-containing RNAs as a hidden layer of the transcriptome. Front Genet 9: 562. doi:10.3389/fgene.2018.00562

Shukla S, Parker R. 2017. PARN modulates Y RNA stability and its 3'end formation. Mol Cell Biol 37: e00264-17. doi:10.1128/MCB $.00264-17$

Sun Y, Zhang Y, Aik WS, Yang XC, Marzluff WF, Walz T, Dominski Z, Tong L. 2020. Structure of an active human histone pre-mRNA 3'-end processing machinery. Science 367: 700-703. doi:10 .1126/science.aaz7758

Tan EM, Kunkel HG. 1966. Characteristics of a soluble nuclear antigen precipitating with sera of patients with systemic lupus erythematosus. J Immunol 96: 464-471.

Tang W, Kannan R, Blanchette M, Baumann P. 2012. Telomerase RNA biogenesis involves sequential binding by $\mathrm{Sm}$ and Lsm complexes. Nature 484: 260-264. doi:10.1038/nature10924

Tani T, Ohshima Y. 1989. The gene for the U6 small nuclear RNA in fission yeast has an intron. Nature 337: 87-90. doi:10.1038/ 337087a0

Tharun S, He W, Mayes AE, Lennertz P, Beggs JD, Parker R. 2000. Yeast $\mathrm{Sm}$-like proteins function in mRNA decapping and decay. Nature 404: 515-518. doi:10.1038/35006676
Tharun S, Muhlrad D, Chowdhury A, Parker R. 2005. Mutations in the Saccharomyces cerevisiae LSM1 gene that affect mRNA decapping and $3^{\prime}$ end protection. Genetics 170: 33-46. doi:10.1534/ge netics.104.034322

Tickle IJ, Flensburg C, Keller P, Paciorek W, Sharff A, Vonrhein C, Bricogne G. 2017. STARANISO. Global Phasing Ltd., Cambridge, United Kingdom.

Tickle IJ, Flensburg C, Keller P, Paciorek W, Sharff A, Vonrhein C, Bricogne G. 2018. STARANISO. Global Phasing Ltd., Cambridge, United Kingdom.

Veretnik S, Wills C, Youkharibache P, Valas RE, Bourne PE. 2009. Sm/ Lsm genes provide a glimpse into the early evolution of the spliceosome. PLoS Comput Biol 5: e1000315. doi:10.1371/journal pcbi. 1000315

Vindry C, Marnef A, Broomhead H, Twyffels L, Ozgur S, Stoecklin G, Llorian M, Smith CW, Mata J, Weil D, et al. 2017. Dual RNA processing roles of Pat1b via cytoplasmic Lsm1-7 and nuclear Lsm28 complexes. Cell Rep 20: 1187-1200. doi:10.1016/j.celrep .2017 .06 .091

von Roretz C, Di Marco S, Mazroui R, Gallouzi IE. 2011. Turnover of AU-rich-containing mRNAs during stress: a matter of survival. Wiley Interdiscip Rev RNA 2: 336-347. doi:10.1002/wrna.55

Wilkins MR, Gasteiger E, Bairoch A, Sanchez JC, Williams KL, Appel RD, Hochstrasser DF. 1999. Protein identification and analysis tools in the ExPASy server. Methods Mol Biol 112: 531-552. doi:10.1385/1-59259-584-7:531

Wilusz CJ, Wilusz J. 2013. Lsm proteins and Hfq: life at the $3^{\prime}$ end. RNA Biol 10: 592-601. doi:10.4161/rna.23695

Wu DH, Jiang SM, Bowler MW, Song HW. 2012. Crystal Structures of Lsm3, Lsm4 and Lsm5/6/7 from Schizosaccharomyces pombe. PLoS One 7: e36768. doi:10.1371/journal.pone.0036768

Wu D, Muhlrad D, Bowler MW, Jiang S, Liu Z, Parker R, Song H. 2014 Lsm2 and Lsm3 bridge the interaction of the Lsm1-7 complex with Pat1 for decapping activation. Cell Res 24: 233-246. doi:10.1038/ cr.2013.152

Zhou L, Hang J, Zhou Y, Wan R, Lu G, Yin P, Yan C, Shi Y. 2014a. Crystal structures of the Lsm complex bound to the $3^{\prime}$ end sequence of U6 small nuclear RNA. Nature 506: 116-120. doi:10 .1038 /nature12803

Zhou L, Zhou Y, Hang J, Wan R, Lu G, Yan C, Shi Y. 2014b. Crystal structure and biochemical analysis of the heptameric Lsm1-7 complex. Cell Res 24: 497-500. doi:10.1038/cr.2014.18

Zimmermann L, Stephens A, Nam SZ, Rau D, Kubler J, Lozajic M, Gabler F, Soding J, Lupas AN, Alva V. 2018. A completely reimplemented MPI bioinformatics toolkit with a new HHpred server at its core. J Mol Biol 430: 2237-2243. doi:10.1016/j.jmb.2017.12.007 

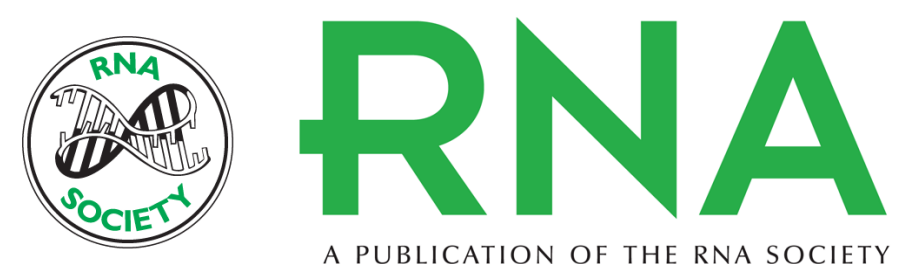

A PUBLICATION OF THE RNA SOCIETY

\section{Molecular basis for the distinct cellular functions of the Lsm1-7 and Lsm2-8 complexes}

Eric J. Montemayor, Johanna M. Virta, Samuel M. Hayes, et al.

RNA 2020 26: 1400-1413 originally published online June 9, 2020

Access the most recent version at doi:10.1261/rna.075879.120

\section{Supplemental http://rnajournal.cshlp.org/content/suppl/2020/06/09/rna.075879.120.DC1 Material}

References This article cites 70 articles, 27 of which can be accessed free at: http://rnajournal.cshlp.org/content/26/10/1400.full.html\#ref-list-1

Open Access Freely available online through the RNA Open Access option.

Creative This article, published in RNA, is available undera Creative Commons License Commons (Attribution 4.0 International), as described at

License http://creativecommons.org/licenses/by/4.0/.

Email Alerting Receive free email alerts when new articles cite this article - sign up in the box at the Service top right corner of the article or click here.

To subscribe to $R N A$ go to:

http://rnajournal.cshlp.org/subscriptions 